\title{
Diaspora Externalities and Technology Diffusion
}

E. Lodigiani

Discussion Paper 2008-8

Département des Sciences Économiques

de l'Université catholique de Louvain 


\title{
Diaspora Externalities and Technology Diffusion*
}

\author{
Elisabetta Lodigiani ${ }^{a, b}$ \\ ${ }^{a}$ Department of Economic Sciences, Université Catholique de Louvain \\ ${ }^{b}$ Centro Studi Luca d'Agliano, Università degli Studi di Milano
}

February 2008

\begin{abstract}
The aim of this paper is to highlight the positive and important role that skilled migration can have on TFP growth in the sending countries, when diaspora effects in technology diffusion are introduced. To investigate our issue, we start from a previous paper by Vandebussche, Aghion and Costa Meghir (2006), in which they examine the contribution of human capital to economic growth, where technological improvements are a result of a combination between innovation and imitation. Considering the impact of a positive externality on growth due to skilled migration, we show that a marginal increase in the stock of skilled human capital contributes more to productivity growth if a state is closer to the technological frontier and migration should raise growth in area far from the frontier. Also, we provide evidence in favour of this prediction by using a panel dataset covering 92 countries between 1980 and 2000. Even if our empirical study has a lot of shortcomings, given the small number of countries and
\end{abstract}

*I am greatly indebted to Frédéric Docquier and Giorgio Barba Navaretti for their precious comments and for many insightful discussions. I thank also Michel Beine and Fati Shadman-Mehta for their helpful suggestions. The usual disclaimers apply. I acknowledge financial support from the Belgian French-Speaking Community (ARC grant 03/08-302 "New macroeconomic approaches to the development problem"). Correspondence address: Université Catholique de Louvain, Department of Economic Sciences, 3 Place Montesquieu, B-1348 Louvain-La-Neuve, Belgium. Email: elisabetta.lodigiani@uclouvain.be 
of time periods due to the current availability of data in the existing cross-country datasets, this work is the first one that attempt to investigate the relationship between growth and networks externalities, underlying the importance of the skilled diaspora in the transfer of ideas.

JEL Classification: F22, O15, O30, O40, Z13

Keywords: Economic growth, Imitation, Innovation, Migration, Brain drain, Diaspora 


\section{Introduction}

The migration of high skilled people from less to more developed countries has long been a critical issue and an unsolved problem. In the 70's, the brain drain was unambiguously seen as a problem for the source country. On the contrary, it has recently been claimed that emigration could also benefit the sending country trough "incentive and feedback effects". The aim of this chapter is to highlight the positive and important role that skilled migration can have on TFP growth in the sending countries, when diaspora effects in technology diffusion are introduced. The basic idea is that skilled emigrants can have an important role in the transfer of knowledge and technology from the most to the less developed world through more or less informal networks. Therefore, even if the loss of human capital can slow down the growth process, the source economy can benefit from the stimulation of growth through imitation and knowledge diffusion. To investigate our issue, we start from a previous paper by Vandebussche, Aghion and Costa Meghir (2006), in which they examine the contribution of human capital to economic growth, where technological improvements are a result of a combination between innovation and imitation (adoption), a specification that they share with Benhabib and Spiegel (1994), Acemoglue Aghion and Zilibotti (2006) and that of course trace its root to the seminal paper by Nelson and Phelps (1966). Considering that both activities, i.e. imitation and innovation, make use of both high skilled and unskilled labor, Vandebussche, Aghion and Costa Meghir show that skilled labor has a higher growth enhancing impact closer to the technological frontier (and conversely the growth-enhancing effect of unskilled human capital decreases with the proximity to the frontier), given the assumption that innovation makes a relative more intensive use of skilled labor.

In such a framework, we consider the impact of a positive externality on growth due to skilled migration. We show that a marginal increase in the stock of skilled human capital contributes more to productivity growth if a state is closer to technological frontier (and vice versa) and migration should raise growth in area far from the frontier. Also, we provide evidence in favour of this prediction by using a panel data set covering 92 countries between 1980 and 2000. Even if our empirical analysis has a lot of shortcomings, given the small number of countries and of time periods due to the current availability of data in the existing cross-country data sets, this is the first study that attempts to investigate the relationship between growth and network exter- 
nalities, underlying the importance of the skilled diaspora in the transfer of ideas.

The chapter is organized as follows.

In section 2, we introduce some stylized facts. Then, in section 3 , we present a theoretical model that shows how skilled migration can have an ambiguous impact on growth. In section 4, we try to give empirical evidence to our main theoretical predictions. Section 5 concludes.

\section{Some stylized facts}

Even if an analytical study of the potential gain from migration due to diaspora externalities is still far from being systematic, there are some case studies that show how diaspora can be an important source for contributions to the homeland. In particular, diaspora can create technology and knowledge transfer without (both) being embedded in trade and FDI, but (and also) relying on more or less informal networks, interested in helping to promote the scientific and economic development of their home countries (Meyer and Brown, 1999). This section builds from some country case studies to illustrate how diaspora could induce technology transfer.

People's Republic of China. The important role of the Chinese diasporic networks is very well known. The 'bamboo network' in favoring investment into China is very well documented. At the same time, the Chinese Business Sphere (consisting of business populations in the People's Republic of China, Taiwan, Hong Kong, Macao, ASEAN countries, and Indochina), where Chinese are doing business using contact networks, has become one of the most important economic power blocs in the world. Chinese diaspora played a critical role in knowledge-based growth and the specific patterns of engagement of the diaspora with the origin country, had its implications for technology transfer. In the Chinese case, "the technology transfer has been principally at the firm level, especially in export led manufacturing" (Kapur, 2001). But more generally, the large size and the high-skill composition of the diaspora abroad played a critical role in the knowledge exchange process thanks to the activities of the Overseas Chinese professional (OCP) formal and informal associations and to the pro-active role of the Chinese government in exploiting the diaspora advantages. To give a generally idea of the Chinese diaspora potentiality, we refer to Biao (2005) to describe its magnitude and composition. Biao underlines that Overseas Chinese professionals (OCPs) 
can be divided into two subgroups: those who left before and after the reform movement initiated in 1978. A report by OCAO in early 2002 indicates that among the estimated 30 million of overseas Chinese who left before the Reform, there are about "600,000 overseas Chinese technology personnel in Western developed countries. There are 450,000 in the USA alone, including 30,000 of world-class professionals, making up about one quarter of the 130,000 first-rank scientists and technology personnel in the USA" (OCAO 2002 in Biao, 2006). According to Biao" by 2003, an accumulated number of more than 700,000 students went overseas for study, and about 180,000 of them returned to China on a long-term basis, therefore creating a pool of OCPs of 520,000 (including students who may return later). Combining the new OCPs with those who left before 1949 (estimated to be 600,000), we estimate that the total OCPs at the current time (by end of 2003) is 1.1 million, including 140,000 who left after 2000, who are pursuing degrees or just graduated, and therefore may not be regarded as fully fledged OCP members." The majority of them resides in the United States followed by Japan and Canada. Biao's survey indicates that OCPs have in general a very high education, in fact 78.2 percent hold a Ph.D, 16.4 percent have Master's and only 5.5 percent have only Bachelor's degrees. In terms of the area of study and specialization, Biao says that the OCAO database suggests that a 4 percent of OCPs is in the field of social sciences and humanities and the strong majority is in science and engineering. During the latest years, the government has very well understood the great potentiality of the diaspora abroad and he has played a pro-active role in developing initiatives who aim at promoting knowledge exchange through institutional structures, policies centered on incentives targeted to skilled OCPs, concrete program activities and official website. ${ }^{1}$ Associations beyond the Government are also very numerous and they played an important role in seeking to match needs in the homeland with diaspora skills and knowledge (for instance inviting Chinese

\footnotetext{
${ }^{1}$ Many policies focus on providing incentives to OCP returnees, other policies seek to liberalize freedom of movement for OCPs in the PRC, including entry and exit, or they offer OCPs opportunities for economic returns and career development for example through collaborative projects etc. Program activities include funded short-term visits, collaborative research projects, OCP research projects conducted in the PRC, contractual professorial and research chairs in the sciences, or program activities focused on diaspora networking, such as visiting delegations, business venture conventions, scientific conferences, industrial parks targeted to OCP-initiated ventures See Biao (2006) for a detailed description of the initiatives
} 
scholars for knowledge exchange in the hostland or organising delegations to the homeland). ${ }^{2}$ Chinese government has recognized the importance of OCP associations and he seeks to exploit them in building transnational networks. Despite a lot of governmental initiatives, Biao underlines that these policies and programs have some limits, for instance the PRC's efforts seem to be exclusively focused on science and technology, ignoring potential contributions in the social sciences and through diaspora philanthropy. Moreover they are mainly focused on profitable projects and "narrowly on "return", regardless of whether it is permanent or temporary ". Biao then suggests that a longer-term approach, that better links OCP programs to the dynamism of the global economy, has to be taken into account as "the fundamental goal of promoting knowledge exchange is not to import knowledge per se, but to develop the local RD capacity in a sustainable manner".

India. According to Pandey et al. (2006)" more than 20 million people of Indian origin live in 70 countries. They represent more than 40 percent of the population in Fiji, Guyana, Mauritius and Surinam and account for prominent minority communities in Australia, Canada, Malaysia, South Africa, Sri Lanka, Uganda, The United Kingdom and the United States. The earnings of the 20 million-strong diaspora are equivalent to about two-thirds of the GDP of India, with a population of more than one billion." The Indian diaspora in the United Kingdom is very significant, in particular in the information technology (IT) and in the medicine sector. Chanda (2001) has estimated that there are at least 60,000 doctors of Indian origin in the UK, equivalent to 12 percent of the total stock of doctors in India and to the 30 percent of registered doctors in the U.K. ${ }^{3}$ The Indian ministry of External Affairs underlines that in 2000, 11,474 Indian professionals entered the IT sector in the United Kingdom (on a total of 18,250 expatriate IT professionals). In 2000, "there were more than 300 influential, nonresident Indian

\footnotetext{
2"It is estimated that there are currently more than 10,000 overseas Chinese associations, including more than 100 global organizations (i.e. not confined to any particular country) (Xie Chenjia 2002)" with a major development during the last twenty years. Most associations are in the area of science and engineering, and USA is the dominant location. For instance "The Chinese Association for Science and Technology, USA, was set up in New York in 1992, and has now more than 1,500 members in 27 states, with more than ten regional or disciplinary branches"

${ }^{3}$ Commander et al.(2003) explain that "according to the Medical Council of India there were 503,900 registered medical practitioners in India (Health Information of India 1998) in 1998, and the General Medical Council in the UK has a total of 193,000 doctors on their register with 5,700 overseas doctors on limited registration (Five Year Review 1995-2000)".
} 
business people and 150 other very rich and prominent Indians in the United Kingdom". Also in other developed countries, in particular in the United States and in Canada, Indians have been very successful in the KnowledgeIntensive sectors. In particular in the IT sector a critical number of Indians are chief executive officers and senior executives at American technological companies. Some Indian people are professors at important engineering and technology institutes, such as Massachussetts Institute of Technology and Stanford University. The Indian diaspora is also important in the medical sector and in the business sector.

The very important role of the Indian Diaspora in the Indian IT sector has been widely discuss (see Saxenien, 1999). According to Kuznetsov and Sabel (2006), the Indian software industry grew 40 percent a year in the 1990s; at the same time, "employment grew from 56,000 to 360,000 absorbing most of the 75,000 new information technology graduates India produces every year. The number of software firms more than quadrupled, from 700 to more than 2,800, and the largest firms, such as Wipro and Infosys, are undertaking increasingly complex and valuable projects". Such a growth was possible thanks to the policy government on higher education and to the Indian executives of Us-based industry that gave their companies the confidence to outsource in India. The Indian diaspora was also important to help Indian firms to meet U.S. quality and deliver requirements. Pandey underlines that the Indian Diaspora establishes the International School of Business (ISB). Many Indian professors that teach in the United States, in the UK or in Canada, take one or two-term sabbatical to teach at ISB. Furthermore, many Indians living abroad returned to India to join large companies such as General Eletric, Intel or IBM. According to AnnaLee Saxenian (2002), 73 percent of the Indian origin entrepreneurs in the IT sector in Silicon Valley inquired in her survey, has from 1 to 9 friends who came back to India to start a company, 52 percent travelled to India on business at least once a year, 27 percent has regular exchanging information on job and business opportunities in the United States with those back home, 33 percent reported regular exchanges of information on technology and 46 percent at least once helped domestic Indian businesses by arranging a contract. In terms of investment, 23 percent had invested their own money into Indian start-ups

\footnotetext{
4" These include Gulu Lalvani (eletronics industry), Manubhai Madhvani (sugar industry), Lakshmi Mittal (iron and steel industry), Lord Swaraj Paul (manufacturing and supply of steel and engeneering product), Jasminder Singh (hotel industry)(Pandey et al., 2006 )
} 
or venture funds more than one occasion. Although these figures may not represent the situation of all emigrant IT professionals, this survey makes clear that Indian Diaspora has established wide and proficous connections with the homeland. The win-win situation created by the Indian Diaspora was supported also by the Indian Government. In fact not only he made efforts to incentivate investments in Human Capital, but also, recognizing the importance of the mobility of skilled labor, India has made systematic efforts to push for WTO negotiations on services and the mobility of the highly skilled, and to persuade the West to relax restrictions on the migration of professionals, as evidenced by a speech by then Indian Prime Minister Atal Bihari Vajpayee (2001).

\section{Philippine}

The Filipino diaspora is very large and includes a large share of the most productive age group $(25-44)$ and the most educated. The Commission on Filipinos Overseas estimates a 7,924,188 stock in the December 2005. Even if recognizing the importance of the diaspora, the government has done only discontinuous program to incentivate knowledge exchange with his diaspora. Opiniano and Castro (2005) underline that at the end of the 80's the Science and Technology Advisory Council encourages overseas Filipino scientists to form their own associations and initiate knowledge transfer. But among all the chapters started, only one active chapter remains, in Japan, which provides training programs and meetings around specific research topics, it has been developing a database of Filipino researchers, and it awards research grants to science majors in the Philippines. During the same period, UNDP's Transfer of Knowledge Through Expatriate Nationals (TOKTEN) program (1988-1994), funded highly skilled expatriates to undertake short-term time period consultancies, but the program was discontinued when the head of the Department of Foreign Affairs, left this post. From 1994 to 1999 also a knowledge transfer program called the Balik Scientist program was developed by the Department of Science and Technology, with the support from the Department of Foreign Affairs. During this period, the program sustained short (at least 1 month) and long term (at least 2 years) assignments for 84 overseas Filipino scientists, who benefited 23 academic institutions, 22 hospitals, 12 government agencies, 11 private sector companies, and a range of government programs. On the other hand overseas Filipinos associations start to organise knowledge transfer activities, such as teacher training, special training events and short-term consultancies. As an example the Brain Gain Network of engineers, scientists, and high-technology organizations seeks to create connec- 
tions between expatriate Filipinos and counterparts in the Philippines for the purpose of knowledge exchange, encouraging venues for business networking and joint collaboration. The Association of Filipino Teachers (AFTA) based in New York City began the Balik-Turo (or Return to Teach) program in 1993 to train teachers in the Philippines. However up to now, despite a large skilled diaspora, it has not been recognize any big real gain from Filipino Diaspora. A proactive and integrated policy to attract knowledge transfer (e.g., incentives for migrants involved in these activities) has not yet been developed. On the other side, the bad performance of the domestic economy remains a big problem. Poor conditions in the Philippines are disincentives for migrants either to return or to transfer knowledge.

Other case studies can be described as successful, such as China and India, or unsuccessful, such as Philippine, Armenia or Afghanistan. ${ }^{5}$ But, what are the general conditions to have a successful diaspora? To give a precise answer to this question is very difficult, because every case has its own feature. The home country size seems to be an important factor for a successful diaspora. Large countries have larger diasporas and therefore larger networks. Intuitively the benefit of the networks is increasing in its network size, therefore large countries are more likely to benefit from the diaspora. But network size is just one factor. Other conditions that contribute to the potential importance of the diaspora are related to its education/skill and income, to "the activities in which the diaspora is engaged (skilled versus non-skilled labor; tradable sector versus non-tradable; hierarchy in the product cycle life-new industries versus mature industries) and the income gap between the host and the destination country (An immigrant from Ghana to the US is likely to have different effects than an immigrant from the same country to Nigeria)"' (Kapur, 2001). Also factors that contribute to the realized influence of diaspora are relevant. In particular, the home country conditions, the level of democracy and development are key factors on the propensity of the migrant to contribute from overseas. As an example, Biao suggests that after 1989 Tian'anmen Square movement had a negative influence on OCPs' incentives to return, at least in the years immediately following. For Philippines, Opiniano and Castro maintain that the continuing bad performance of the Philippine economy and the poor quality of life disincentive a lot skill transfer and investment. At the same time the successful Indian and Chinese

\footnotetext{
${ }^{5}$ See Kuznetosov (2006), Brinkerhoff (2006), for further examples
} 
diasporas both modified their attitude towards the source country when the prospects of their home countries improved.

This study mainly focuses on the factors that contribute to the potential importance of the diaspora and tries to understand which countries can benefit from the skilled diaspora in the developed world.

\section{The model}

The aim of this theoretical session is to investigate the role that skilled migration can have on TFP growth in the sending countries, when diaspora effects in technology diffusion are introduced. In order to satisfy our purpose, we start from a previous paper by Vandebussche, Aghion and Costa Meghir (2006), in which they examine the contribution of human capital to economic growth and where technological improvements are a result of a combination between innovation and imitation (adoption), a specification that they share with Benhabib and Spiegel (1994), Acemoglue Aghion and Zilibotti (2006) and that of course traces its roots to the seminal paper by Nelson and Phelps (1966). This paper has been chosen, because, in our opinion, it belongs to the most appropriated framework (the growth schumpeterian paradigm) to study the impact of network externalities on growth. First, as underlined by Aghion and Howitt (2005), the schumpeterian paradigm is the only one compatible with the empirical literature on growth and human capital. There is no effect of human capital on long-run GDP growth rates (the empirical literature of the 1990s is mixed) but there is an effect in level (the crosscountry correlation between the log of GDP growth rate and the log of the proportion of tertiary skilled is almost equal to one). The long run growth rate is determined by the leader but disparities are endogenous. Second, it is the only model compatible with an international balanced growth path. In the long-run, disparities across nations are stationary. All other frameworks (AK, Lucas, product variety) predict heterogeneous country-specific growth rates. If growth rates diverge, disparities between countries tend to infinity (some countries economically disappear). The schumpeterian framework is the only one which accounts for interdependencies between countries and balanced growth. As Aghion and Howitt conclude "Schumpeterian paradigm provides a unifying framework for thinking about and designing appropriate (context-dependent) growth policy. In particular, the paradigm produces precise testable predictions as to how growth-maximizing policies (e.g, com- 
petition and entry policies, the allocation of education funding or the design of macroeconomic policies) should vary with a country's or sector's distance to the technological frontier, and/or with the country's level of financial development.... When comparing the Schumpeterian paradigm to the AK or product diversity models of endogenous growth, we have concluded that the former does a better job at delivering systematic and yet context dependent policy prescriptions." We focus now on our model.

\subsection{Agents and Production}

Consider a world consisting of two types of economies, one leader economy (for concreteness, we can think of the United States) and technological follower economies that take the leader's case as given. The economies are populated by workers and entrepreneurs. Skilled workers are allowed to migrate from the less technological economy to the leader economy. Time is discrete and all agents live only for one period. We assume that, in the source country, the pre-migration worker population is exogenous and constant over time. It is made up of skilled workers $\bar{S}$ and unskilled workers $\bar{U}$, with $\bar{S}+\bar{U}=N$. Unskilled workers are immobile, $M_{u, t}=0$, whereas the skilled ones are mobile, $M_{s, t}>0\left(M_{s, t}\right.$ represents the stock of skilled worker abroad at time $t$ ). After migration, at time $t$, in aggregate an economy is endowed with $s$ skilled and $u$ unskilled units of labor. ${ }^{6}$ We make the hypotheses that each worker in the economy is endowed with only one unit of labor, therefore $s$ and $u$ represent respectively the fraction of workers that are skilled and unskilled. After migration, the fraction of skilled workers $s$ in the economy, at time $t$, is given by:

$$
s_{t} \equiv \frac{\bar{S}-M_{s, t}}{\bar{S}+\bar{U}-M_{s, t}}=\frac{\bar{S}-M_{s, t}}{N-M_{s, t}}
$$

whereas the fraction of unskilled workers is given by:

$$
u_{t} \equiv \frac{\bar{U}}{\bar{S}+\bar{U}-M_{s, t}}=\frac{N-\bar{S}}{N-M_{s, t}}
$$

\footnotetext{
${ }^{6}$ In this model we consider both the fraction of skilled labor and the number of skilled migrants as given. We disregard any problems of incentive effects on human capital accumulation due to emigration prospects
} 
Following Vandenbussche, Aghion and Costa Meghir (2006), henceforth VAM, one final good is produced competitively using a continuum of intermediate inputs, indexed from 0 to 1 , and a fixed factor (typically land), that without loss of generality is set equal to 1, according to the following Cobb-Douglas production function:

$$
y_{t}=l_{t}^{1-\alpha} \int_{0}^{1} A_{i, t}^{1-\alpha} x_{i, t}^{\alpha} d i
$$

where $\alpha \in(0,1), x_{i, t}$ is the quantity of intermediate input produced in sector $i$ at date $t, A_{i, t}$ is the productivity in sector $i$ (and it measures the quality of the intermediate input $i$ in producing the final good), and $l_{t}$ is the amount of land used in the final production at time $t$. We normalize the total supply of land to one $\left(l_{t}=1 \forall t\right)$. The final good can be used either for consumption, or as an input in the process of production of intermediate goods. We normalize the price of the final good to 1 . In each intermediate sector $i$ only one firm (a local monopolist) is active in each period, and it produces intermediate input $i$ with productivity $A_{i, t}$ using final good as input with a one-to-one technology. ${ }^{7}$ Since the final good sector is competitive, each intermediate (local) monopolist $i$ at date $t$ faces the inverse demand schedule:

$$
p_{i, t}=\frac{\partial y_{t}}{\partial x_{i, t}}=\alpha A_{i, t}^{1-\alpha} x_{i, t}^{\alpha-1}
$$

At the same time, the local monopolist chooses $x_{i, t}$ in order to maximize its profit:

$$
\underset{x_{i, t}}{\operatorname{Max}}\left(p_{i, t} x_{i, t}-x_{i, t}\right)
$$

Then profit maximization by intermediate producers yields the equilibrium demand for good $i$

$$
x_{i, t}=\alpha^{\frac{2}{1-\alpha}} A_{i, t}
$$

${ }^{7}$ To better explain, we consider that in each intermediate sector $i$, only one firm has access to the most productive technology, $A_{i, t}$, so this "leading firm" will have monopoly power. Moreover, each leading firm has access to a technology to transform one unit of the final good into one unit of intermediate good of productivity $A_{i, t}$. 
and the corresponding equilibrium profit in intermediate sector $i$ is equal to:

$$
\pi_{i, t}=\varsigma A_{i, t}
$$

where $\varsigma \equiv\left(\frac{1}{\alpha}-1\right) \alpha^{\frac{2}{1-\alpha}}$

Substituting for $x_{i, t}$ in the production function for final output, we obtain:

$$
y_{t}=\zeta A_{t}
$$

where

$$
A_{t}=\int_{0}^{1} A_{i, t} d i
$$

is the average productivity at time $t$ and $\zeta=\alpha^{\frac{2 \alpha}{1-\alpha}}$ is a constant

\subsection{Productivity dynamics}

At the initial stage of each period firm $i$ decides on its demand for skilled and unskilled workers for the purpose of maximizing productivity (and thereby profit). We assume that productivity can be improved by a combination of (i) innovation upon the local technological frontier and (ii) imitation/adoption from the world technological frontier. Both activities use skilled and unskilled labor as inputs. Following Vandenbussche, Aghion and Costa Meghir (who in turn followed Benhabib and Spiegel (2004) and Acemoglu and al. (2006)), technological progress is given by:

$$
A_{i, t}=A_{i, t-1}+\varphi\left(M_{s, t}\right) u_{m, i, t}^{\sigma} s_{m, i, t}^{1-\sigma}\left(\bar{A}_{t-1}-A_{t-1}\right)+\gamma u_{n, i, t}^{\phi} s_{n, i, t}^{1-\phi} A_{t-1}
$$

where: i) $\bar{A}_{t-1}$ represents the world technological frontier at time $t-1$ ii) $A_{t-1}$ is the country's productivity frontier at the end of period $t-1$ iii) $u_{m, i, t}$ and $s_{m, i, t}$ are the amounts of labor input (respectively unskilled and skilled) used in imitation in sector $i$ at time $t$

iv) $u_{n, i, t}$ and $s_{n, i, t}$ are the amounts of labor input (respectively unskilled and skilled) used in innovation activities in sector $i$ at time $t$

v) $\gamma>0$ measures the relative efficiency of innovation compared to imitation in the productivity growth process.

The elasticity of skilled labor is assumed to be higher in innovation than in imitation, i.e. $\phi<\sigma$. This assumption is made to reflect that skilled workers 
are relative more productive in innovation than in adoption of existing techniques. This is a plausible assumption because we can imagine that skilled human capital is better suited to innovation, as adoption and imitation are relatively straightforward activities (compared to innovation). ${ }^{8,9}$

Furthermore, as we can see from equation (6), following Benhabib and Spiegel and VAM, we make the standard assumption that the world frontier technology diffuses from the most developed economy to the less one with a lag of one period and the rate of diffusion is positively related to the size of the gap between the two economies, i.e. the higher the distance to the frontier, the more technology can be adopted from abroad. This is quite intuitive, since a larger technological gap means that more innovations can be usefully adopted from abroad. Local innovation, instead, becomes more productive the higher the own technology level, $A .^{10}$

${ }^{8}$ This assumption follows from VAM, but also refers to Acemoglue, Aghion and Zilibotti (2006) and to the seminal paper of Nelson and Phelps (1966). As Acemoglue et al. underlines, "Nelson and Phelps (1966) ranks activities according to the degree they required adaptation to change. They write :" At the bottom of this scale are functions that are highly routinised...In the other direction on this scale we have, for example, innovative functions which demand keeping of improving technology..." (pag. 69). They argue that the importance of human capital increases with the innovative content of the tasks performed, or with the extent to which "it is necessary to follow and to understand new technological developments" (pag.69)."

${ }^{9}$ The assumption that innovation makes a relatively more intensive use of skilled labor, implies that an increase in skilled labor will induce an allocation of both labor input toward innovation (and vice versa). This assumption is fundamental to show that what is important for growth, it is not only a level effect, but a composition effect of human capital: holding its level constant, the growth-enhancing properties of human capital depend on both its composition and distance to the frontier. In particular, the growth enhancing effect of skilled human capital is positively related to the distance to the frontier (and vice versa). If the two activities would have equal factor intensities, the ratios of unskilled to skilled human capital would be constant across activities and the contribution of human capital to growth, given the ratio of skilled to unskilled labor, would depend only by a "level" effect of skilled human capital, weighed by, for the one allocated in imitation, the distance from the frontier and, for the one allocated in innovation, by its relative efficiency in the production process $\left(g=\varphi\left(M_{s}\right)\left(\frac{u}{s}\right)^{\phi}\left[s_{m}\left(\frac{1}{a}-1\right)+\gamma s_{n}\right]\right.$ to be compared by the growth rate in session 3.3 )

${ }^{10}$ This assumption is quite standard in the "Schumpeterian"'growth theory and actually it traces its backs to Gerschenkron 's "'Advantage of backwardness" in his famous Economic Backwardness in Historical Perspective (1962), where he explained that relatively backward countries, such as Germany France and Russia during the 19th century, could rapidly catch-up to more advanced economies by undertaking a lot of investments to implement innovations from the frontier. For further details see Aghion and Howitt,2005 
Extending VAM, in accordance with all the stylized facts described in section 2, we allow for a further effect on adoption due to migration i.e. the capacity to adopt depends also on a positive externality due to the skilled diaspora abroad $\varphi\left(M_{s, t}\right)$, with $\varphi^{\prime}\left(M_{s, t}\right)>0$ and $\varphi^{\prime \prime}\left(M_{s, t}\right)<0$ (the larger the diaspora, the lower the information costs for technology diffusion, therefore the effect of the externality will be increasing in the numbers of skilled migrants, but less increasing once that a certain number of migrants has been reached)

\subsection{Optimal firms' behaviour}

The wage of skilled and unskilled labors are respectively given by $w_{s, t} \bar{A}_{t-1}$ and $w_{u, t} \bar{A}_{t-1}$. From equation (6), the two different kinds of labor inputs are employed in augmenting productivity, $A_{i, t}$. From equation (4), total operating profit depends on the productivity level. Solving the model consists in finding the optimal amount of skilled and unskilled labor that has to be allocated across imitation and innovation in order to maximize profits, for a total given labor supply and at a given distance to the technological frontier. Firms live for one period only and thus each producer of good $i$ maximizes current profit net of labor costs of productivity improvements:

$\underset{u_{m, i, t}, s_{m, i, t}, u_{n, i, t}, s_{n, i, t}}{\operatorname{Max}} \varphi\left(M_{s, t}\right) u_{m, i, t}^{\sigma} s_{m, i, t}^{1-\sigma}\left(\bar{A}_{t-1}-A_{t-1}\right)+\gamma u_{n, i, t}^{\phi} s_{n, i, t}^{1-\phi} A_{t-1}-W_{i, t}$

where

$$
W_{i, t}=\left[w_{u, t}\left(u_{n, i, t}+u_{m, i, t}\right)+w_{s, t}\left(s_{n, i, t}+s_{m, i, t}\right)\right] \bar{A}_{t-1}
$$

Given that:

1) all the intermediate firms face the same maximization problem (so in equilibrium $u_{m(n), i, t}=u_{m(n) t}$ and $s_{m(n), i, t}=s_{m(n) t}$ therefore subscript $i$ can be eliminated)

2) there is a mass 1 of intermediate firms, so labor market equilibrium implies: $s_{t}=s_{n, i, t}+s_{m, i, t}$ and $u_{t}=u_{n, i, t}+u_{m, i, t}$ with $s_{t}+u_{t}=1$ ( $s$ and $u$ describe the fraction of the labor force that is skilled and unskilled).

Assuming an interior solution, the following first-order conditions are obtained:

$$
\begin{aligned}
\varphi\left(M_{s, t}\right) \sigma u_{m, t}^{\sigma-1} s_{m, t}^{1-\sigma}\left(1-a_{t-1}\right) & =\gamma \phi u_{n, t}^{\phi-1} s_{n, t}^{1-\phi} a_{t-1} \\
\varphi\left(M_{s, t}\right)(1-\sigma) u_{m, t}^{\sigma} s_{m, t}^{-\sigma}\left(1-a_{t-1}\right) & =\gamma(1-\phi) u_{n, t}^{\phi} s_{n, t}^{-\phi} a_{t-1}
\end{aligned}
$$


that can be re-written as:

$$
\begin{array}{r}
\varphi\left(M_{s, t}\right) \sigma u_{m, t}^{\sigma-1} s_{m, t}^{1-\sigma}\left(1-a_{t-1}\right)=\gamma \phi\left(u_{t}-u_{m, t}\right)^{\phi-1}\left(s_{t}-s_{m, t}\right)^{1-\phi} a_{t-1} \\
\varphi\left(M_{s, t}\right)(1-\sigma) u_{m, t}^{\sigma} s_{m, t}^{-\sigma}\left(1-a_{t-1}\right)=\gamma(1-\phi)\left(u_{t}-u_{m, t}\right)^{\phi}\left(s_{t}-s_{m, t}\right)^{-\phi} a_{t-1}
\end{array}
$$

where $a_{t-1} \equiv A_{t-1} / \bar{A}_{t-1}$ is an inverse measure of the country's distance to the world technological frontier at $t-1$.

Dividing across equations, we obtain:

$$
\sigma(1-\phi) s_{m, t}\left(u_{t}-u_{m, t}\right)=(1-\sigma) \phi\left(u_{m, t}\left(s_{t}-s_{m, t}\right)\right)
$$

and defining $\Psi=\frac{\sigma(1-\phi)}{\phi(1-\sigma)}>1$ as $\phi<\sigma$, we obtain:

$$
\Psi \frac{u_{n, t}}{s_{n, t}}=\frac{u_{m, t}}{s_{m, t}}
$$

The above equation shows that the ratios of unskilled to skilled employment are proportional across activities and less skilled workers are allocated in imitation due to $\phi<\sigma$.

From (11) we can get easily $u_{m, t}$ in function of $s_{m, t}$ :

$$
u_{m, t}=\frac{\Psi s_{m, t} u_{t}}{s_{t}+(\Psi-1) s_{m, t}}
$$

Substituting (13) in (10), we obtain

$$
(\Psi-1) s_{m, t}=h\left(a_{t-1}, M_{s, t}\right) u_{t}-s_{t}
$$

where

$$
h\left(a_{t-1}, M_{s, t}\right)=\left(\frac{(1-\sigma) \Psi^{\sigma}\left(1-a_{t-1}\right) \varphi\left(M_{s, t}\right)}{(1-\phi) \gamma a_{t-1}}\right)^{\frac{1}{\sigma-\phi}}
$$

which is an increasing function in $M_{s, t}$ and a decreasing function in $a_{t-1}$, i.e. $h_{M_{s, t}}^{\prime}>0$ and $h_{a_{t-1}}^{\prime}<0$.

When both imitation and innovation are performed in equilibrium, relative factor intensities in technology productivity are given by:

$$
\begin{aligned}
\frac{u_{m, t}}{s_{m, t}} & =\frac{\Psi}{h\left(a_{t-1}, M_{s, t}\right)} \\
\frac{u_{n, t}}{s_{n, t}} & =\frac{1}{h\left(a_{t-1}, M_{s, t}\right)}
\end{aligned}
$$


For an interior solution to obtain, $s_{m}$ and $s_{n}$ have not to exceed $s$, i.e. $s_{n}<s$ and $s_{m}<s$ with $s_{m}+s_{n}=s .{ }^{11}$ Then, considering the equilibrium value for $s_{m}$ with these three conditions, we obtain that we have an interior solution if and only if ${ }^{12}$

$$
\frac{h\left(a, M_{s}\right)}{\Psi} \leq \frac{s}{u} \leq h\left(a, M_{s}\right)
$$

From equations (15) and (16), given condition (17), when $u$ increases, firms will reallocate unskilled labor in the imitation sector, since the productivity of unskilled labor is higher in the imitation sector than in the innovation sector, $\sigma>\phi$. Therefore the marginal productivity of skilled labor increases more in imitation than in innovation, attracting skilled labor in the imitation sector. Because there is less skilled labor in innovation, the marginal productivity of unskilled labor decreases in innovation and so even more unskilled labor goes to imitation. At the end, employment of both types of labor input has increased in the imitation sector (and decreased in innovation).

On the opposite, an increase in $s$ leads to an increase in the amount of units of labor, both skilled and unskilled, used in innovation (activities that employed skilled labor more intensively) and to a corresponding decrease in labor input in imitation.

When $a$ increases, $h\left(a, M_{s}\right)$ decreases and both types of work are reallocated from imitation to innovation: far from the technological frontier, the catchup effect for imitation is quite high, therefore for firms it is more convenient to employ more labor input in imitation than innovation. On the contrary, the closer the economy is to the frontier, the more convenient is to increase employment in innovation. ${ }^{13}$

If we consider migration, an exogenous increase in skilled migration, $M_{s}$, leads to a decrease in the fraction of skilled labor, $s$, and therefore to a reallocation of resources toward imitation. See in another way, remembering equations (1) and (2), an increase in migration leads to a decrease in $s$ and

\footnotetext{
${ }^{11}$ for simplicity we omit time index subscripts

${ }^{12}$ That's means that given factor endowments, if a country is too far away from the frontier, it will specialise in imitation. If it is very close to the frontier, it will specialize in innovation. Di Maria and Stryzowski investigate in such a framework what happens in the case of full specialisation: in equilibrium, for any given relative wage, firms specialising in innovation would demand relatively more skilled workers than firms specialising in imitation

${ }^{13}$ For further details see Vandenbussche, Aghion and Costa Meghir, 2006
} 
an increase in $u$ as $s+u=1$, and therefore, for the reasons explained above, to a reallocation of both labor inputs toward imitation.

Moreover, if migration increases, $h\left(a, M_{s}\right)$ increases too and both types of work will be reallocated from innovation to imitation. Therefore, when both imitation and innovation are performed in equilibrium, given $a$, the optimal amount of skilled and unskilled labor in imitation will increase the higher the number of skilled migrants abroad.

\subsection{Main Predictions}

Given the equilibrium productivity growth rate at date $t$ :

$$
g_{i, t}=\int_{0}^{1} \frac{A_{i, t}-A_{t-1}}{A_{t-1}} d i=\frac{A_{t}-A_{t-1}}{A_{t-1}}=g_{t}
$$

by substituting the equilibrium value of $s_{m}$ in (6) we obtain the growth rate of the economy given by:

$$
g=\gamma\left[\phi h\left(a, M_{s}\right)^{1-\phi} u+(1-\phi) h\left(a, M_{s}\right)^{-\phi} s\right]
$$

As in VAM, "a marginal increase in the stock of skilled human capital enhances productivity growth all the more the economy is closer to the world technological frontier. Correspondingly, a marginal increase in the stock of unskilled human capital enhances productivity growth all the more the economy is further away from the technological frontier".

But what about migration? Considering that $\bar{S}+\bar{U}=N$ therefore $s+u=$ $\frac{\bar{S}-M_{s}+\bar{U}}{\bar{S}+\bar{U}-M_{s}}=1$. Equation (18) can be re-written as

$$
g=\gamma\left[\phi h\left(a, M_{s}\right)^{1-\phi}(1-s)+(1-\phi) h\left(a, M_{s}\right)^{-\phi} s\right]
$$

Therefore:

$$
\frac{1}{\gamma} \frac{d g}{d M_{s}}=\frac{\partial g}{\partial h\left(a, M_{s}\right)} \frac{\partial h\left(a, M_{s}\right)}{\partial M_{s}}+\frac{\partial g}{\partial s} \frac{\partial s}{\partial M_{s}}
$$

A marginal increase in the stock of skilled migrants has two effects on growth: one effect is through technological transfer thanks to the diaspora abroad and 
the other one is through the reduction of the fraction of the skilled labor force. If we consider these two effects separately:

$$
\begin{aligned}
& \frac{\partial g}{\partial h\left(a, M_{s}\right)} \frac{\partial h\left(a, M_{s}\right)}{\partial M_{s}}= \\
& \quad=\phi(1-\phi)\left[h\left(a, M_{s}\right)^{-\phi}(1-s)-h\left(a, M_{s}\right)^{-(1+\phi)} s\right] \frac{\partial h\left(a, M_{s}\right)}{\partial M_{s}} \\
& \quad=\frac{\varphi\left(M_{s, t}\right)^{\prime}}{\varphi\left(M_{s, t}\right)} \frac{\phi(1-\phi)}{\sigma-\phi}\left[h\left(a, M_{s}\right)^{1-\phi}(1-s)-h\left(a, M_{s}\right)^{-\phi} s\right]
\end{aligned}
$$

represents the effect of skilled migration through technology transfer. Given our assumptions on the function $\varphi\left(M_{s, t}\right)$ and $\sigma>\phi$, this equation is always positive if $\left[h\left(a, M_{s}\right)^{1-\phi}(1-s)-h\left(a, M_{s}\right)^{-\phi} s\right]>0$, that means for $\frac{s}{u}<h\left(a, M_{s}\right)^{14}$ i.e. if not all the skilled labor is allocated in innovation. The growth enhancing effect is bigger the higher the distance from the technological frontier:

$$
\begin{aligned}
\left(\frac{\partial g}{\partial h\left(a, M_{s}\right)} \frac{\partial h\left(a, M_{s}\right)}{\partial M_{s}}\right) \frac{\partial}{\partial a}= & \frac{\varphi\left(M_{s}\right)^{\prime}}{\varphi\left(M_{s}\right)} \frac{\phi(1-\phi)}{\sigma-\phi}\left[(1-s)(1-\phi) h\left(a, M_{s}\right)^{-\phi}+\right. \\
& \left.+s \phi h\left(a, M_{s}\right)^{-(\phi+1)}\right] \frac{\partial h\left(a, M_{s}\right)}{\partial a}
\end{aligned}
$$

that is always negative, as $h$ is a decreasing function in $a$.

Moreover, the growth enhancing effect is decreasing the higher is $s$ :

$$
\left(\frac{\partial g}{\partial h\left(a, M_{s}\right)} \frac{\partial h\left(a, M_{s}\right)}{\partial M_{s}}\right) \frac{\partial}{\partial s}=-\frac{\varphi\left(M_{s}\right)^{\prime}}{\varphi\left(M_{s}\right)} \frac{\phi(1-\phi)}{\sigma-\phi}\left[h\left(a, M_{s}\right)^{1-\phi}+h\left(a, M_{s}\right)^{-\phi}\right]
$$

that is always negative.

In words, an increase in the supply of skilled labor $s$ attracts more labor inputs into innovation for the reasons explained before. This in turn implies that innovation will increase at the expense of imitation, therefore it is intuitive that the effect of migration through knowledge transfer in imitation is less effective (as the imitation sector is becoming less important). We have the same effect when the distance to the frontier decreases. In fact, far below the technological frontier when the catch-up effect of imitation is sufficiently

\footnotetext{
${ }^{14}$ condition for $s>s_{n}$ given $s=s_{n}+s_{m}$
} 
high, it is more convenient to allocate labor inputs in imitation. However, the closer the economy is at the frontier, the more profitable is to increase the innovation component of productivity growth. Again, the more the innovation component is important, the less is the effect of migration through technology transfer.

The effect of migration through technology transfer is neutral when all the activities are allocated in the innovation sector, i.e. when $\frac{s}{1-s}=h\left(a, M_{s}\right)$, or equivalently for $a=\frac{(1-\sigma) \Psi^{\sigma} \varphi\left(M_{s, t}\right)}{\left(\frac{s}{1-s}\right)^{\sigma-\phi}(1-\phi) \gamma+(1-\sigma) \Psi^{\sigma} \varphi\left(M_{s, t}\right)} \equiv \widehat{a}$, that is an increasing function in $M_{s}$ (the higher is migration, therefore the lower is $s$, the closer to the frontier the country has to be to choose to allocate all the activities in the innovation sector). ${ }^{15}$ However here we rule out this case as for hypothesis we do not consider corner solutions.

Therefore we can establish one of our main result:

Proposition 1 Caeteris paribus, skilled migrants induce a positive effect on productivity growth thanks to their role in transferring technology from abroad. This growth enhancing effect is bigger the more important is the imitation sector in the economy.

Skilled migration has also an effect on the growth rate through the reduction of the skilled labor force. In fact, remembering that

$$
s=\frac{\bar{S}-M_{s}}{\bar{S}+\bar{U}-M_{s}}
$$

Then:

$$
\frac{d s}{d M_{s}}=\frac{-\bar{U}}{\left(\bar{S}+\bar{U}-M_{s}\right)^{2}}
$$

that is always negative, reflecting the fact that migration decreases the fraction of skilled labor.

Finally

$$
\frac{\partial g}{\partial s}=-\phi h\left(a, M_{s}\right)^{1-\phi}+(1-\phi) h\left(a, M_{s}\right)^{-\phi}
$$

\footnotetext{
${ }^{15}$ Considering that $s \quad \equiv \quad \frac{\bar{S}-M_{s}}{\bar{S}+\bar{U}-M_{s}}$, then $\frac{\partial \widehat{a}}{\partial M_{s}}=$ $\frac{(1-\sigma) \Psi^{\sigma} \varphi\left(M_{s, t}\right)^{\prime}\left[\left(\frac{\bar{S}-M_{s}}{\bar{U}}\right)^{\sigma-\phi}(1-\phi) \gamma\right]+(1-\sigma) \Psi^{\sigma} \varphi\left(M_{s, t}\right)\left[(1-\phi)(\sigma-\phi) \gamma \frac{\left(\bar{S}-M_{s}\right)^{\sigma-\phi-1}}{(\bar{U})^{\sigma-\phi}}\right]}{\left[\left(\frac{\bar{S}-M_{s}}{\bar{U}}\right)^{\sigma-\phi}(1-\phi) \gamma+(1-\sigma) \Psi^{\sigma} \varphi\left(M_{s, t}\right)\right]^{2}}>0$
} 
has an ambiguous effect on the growth rate. In fact it will be positive only if $\frac{1-\phi}{\phi}>h\left(a, M_{s}\right)$, i.e. given $h$, if the elasticity of skilled labor in innovation is high enough. Therefore, remembering that $h$ is a decreasing function in $a$, far from the frontier, an increase in $s$ will be growth enhancing only if the induced amount of innovation is enough to compensate for the loss in imitation. ${ }^{16}$ See in another way, we can say that $\frac{\partial g}{\partial s}$ is positive if $a>$ $\frac{(1-\sigma) \Psi^{\sigma} \varphi\left(M_{s, t}\right)}{\left(\frac{\phi}{1-\phi}\right)^{\sigma-\phi}(1-\phi) \gamma+(1-\sigma) \Psi^{\sigma} \varphi\left(M_{s, t}\right)} \equiv \widetilde{a}$, that is an increasing function in $M_{s}$, i.e. caeteris paribus the higher $M_{s}$, an increase in $s$ will be growth enhancing the closer to the frontier. ${ }^{17,18}$

Moreover,

$$
\frac{\partial g}{\partial s} \frac{\partial}{\partial a}=\left[-\phi(1-\phi) h\left(a, M_{s}\right)^{-\phi}-\phi(1-\phi) h\left(a, M_{s}\right)^{-(1+\phi)}\right] \frac{\partial h\left(a, M_{s}\right)}{\partial a}
$$

that is always positive, as $h$ is a decreasing function in $a$, showing the complementarity between $s$ and $a$ : the growth enhancing impact of skilled labor increases with a country's proximity to the frontier. This complementarity arises because the labor reallocation due to a marginal increase in the quantity of skilled labor is larger when the productivity of innovation is higher, and therefore its marginal contribution to growth is larger.

\footnotetext{
${ }^{16}$ This is the main finding of VAM. Given the assumption that imitation is more effective the farther away is the country from the frontier, whereas the effect of innovation is larger the closer the country from the frontier, according to VAM, the growth enhancing properties of human capital depends on both its composition and distance to the frontier. It is reasonable to assume that unskilled human capital is better suited for imitation than to innovation. Therefore in advance economies, where innovation is more important, unskilled human capital contribute little to technological improvement, therefore the relevant margin is not that of total human capital, but that of skilled human capital. Conversely in country far from the frontier, when imitation is more important, the relevant margin is that of unskilled human capital. VAM provide evidence that education has a heterogeneous effect even among the OECD groups of countries. Among many results and specifications, to give an example, in their empirical analysis they consider proximity thresholds and, using Barro and Lee data set, they show that for OECD countries with a tfp level more than 26 $\%$ below that of the US, the impact of higher education is negative on growth

${ }^{17} \frac{\partial \widetilde{a}}{\partial M_{s}}=\frac{(1-\sigma) \Psi^{\sigma} \varphi\left(M_{s, t}\right)^{\prime}(1-\phi) \gamma\left(\frac{1-\phi}{\phi}\right)^{\sigma-\phi}}{\left[\left(\frac{\phi}{1-\phi}\right)^{\sigma-\phi}(1-\phi) \gamma+(1-\sigma) \Psi^{\sigma} \varphi\left(M_{s, t}\right)\right]^{2}}$ On the contrary, $\widetilde{a}$ is also an increasing function in $\phi$, therefore the higher the elasticity of skilled workers in innovation, the less the level of $\widetilde{a}$ required for $\frac{\partial g}{\partial s}>0$

${ }^{18}$ To better clarify, an increse in $s$ is growth enhancing without full specialisation in innovation when $a \in(\widetilde{a}, \widehat{a})$ and $\widetilde{a}<\widehat{a}$ if $\frac{1-s}{s}>\frac{1-\phi}{\phi}$
} 
We can summarize our main results:

- on the one hand skilled migrants induce a positive effect on productivity growth thanks to their role in transferring technology from abroad (if the country is not completely specialised in innovation)(Proposition 1)

- on the other hand skilled migrants reduce the fraction of the skilled labor force in the economy. When the latter is growth enhancing, skilled migration induces a negative effect on growth

Thefore:

- if skilled labor induces a negative effect on growth, i.e. $\frac{\partial g}{\partial s}<0$, migration will have a positive effect on growth (that is likely the farther the country is from the frontier).

- If skilled labor is growth enhancing, $\frac{\partial g}{\partial s}>0$, (that it is more likely when country is closer to the frontier), two opposite effects on productivity growth arise: a growth enhancing effect due to the role of migrants in transferring technology from abroad (that will be smaller the higher is $a$ or $s$ ), a growth decreasing effect induced by the loss of skilled labor (that will be bigger the higher the stock of skilled migrants abroad, i.e. the more negative equation (22)).

Then:

Proposition 2 Skilled migration has an ambiguous impact on productivity growth rate. In fact, it has two effects on growth: one trough technology transfer, always positive, the other trough the reduction of the fraction of skilled labor force, which is negative if $s$ is growth enhancing (that is more likely the country is closer to the frontier).

Main Prediction we want to test Two main predictions emerge from our analysis that we want to test: 1) A marginal increase in the stock of skilled human capital contributes more to productivity growth if a country is closer to the technological frontier and vice versa. Therefore, in our empirical analysis, we want to test whether the interaction term between proximity to the frontier and $s$ is positive. 2) Migration should raise growth in area far from the frontier, that is the coefficient of the interaction term between proximity and migration should be negative. 


\section{Empirical Analysis}

The purpose of this section is to investigate the empirically relationship between migration and growth. As seen in section 3, two main implications emerge from our theoretical analysis: first, skilled migrants induce a positive effect on productivity growth thanks to their role in transferring technology from abroad. This growth enhancing effect is bigger the further away the economy is from the technological frontier. Second, skilled migration can induce a negative effect on TFP growth if skilled labor is growth enhancing and that it is more likely when the country is closer to the frontier. In our empirical analysis, we can test these predictions by regressing a country's TFP growth on its proximity to the frontier, on the interaction between its proximity and both its fraction of skilled human capital and skilled emigration, and on the direct effects of human capital and skilled migration. If the model is correct, we will aspect a negative coefficient for the interaction term between proximity and migration. On the contrary, we expect a positive coefficient for the interaction term between proximity to the frontier and the fraction of skilled human capital.

\subsection{Data description}

We combine different sources to construct our panel data set covering 92 countries between 1980-2000 and we follow the same procedure as in VAM.

GDP and Capital stock data We use GDP and Investment data from the World Development Indicators 2006. This source provides yearly data on total investments from the late of the 1970's (about 100 observations in 1975) and are available for about 150 countries in the recent years. However, it does not provide a measure of capital stock by country. We construct this variable using a classical inventory method, based on the following formula:

$$
K_{i, t}=K_{i, t-1}(1-\delta)+I_{i, t-1}
$$

Initial capital stocks, in 1980, are calculated according to the following formula:

$$
K_{i, 80}=\frac{I_{i, 75-82}}{\gamma+\delta+n}
$$


where $I_{i, 75-82}$ is the average amount of investments through 1975 and 1982, $\gamma$ represents the average rate of economic growth over $1975-1985, \delta$ represents the average rate of population growth over 1975-1985 and $n$ represents the rate of depreciation, set equal to 3 percent. We then apply the capital accumulation function sequentially to compute our measure of capital stocks for the period 1980-2000.

Following VAM, we construct total factor productivity, defined as the (log) output per worker minus (log) capital per worker times the capital share:

$$
\log A_{i, t}=y_{i, t}-0.3 * k_{i, t}
$$

where $\log A_{i, t}$ is the $\log$ of total factor productivity, $y_{i, t}$ represents the log of output per worker, $\log (Y / L)_{i, t}, k_{i, t}$ represents the log of the physical capital stock per worker, $\log (K / L)_{i, t}$. Output per worker is constructed by dividing total GDP (constant 2000 dollar) by the size of the worker population. We take labor shares to be constant across countries and equal to 0.7. Then we define proximity to the technological frontier as the ratio of a country's TFP level to that of the US.

\section{Human Capital and Migration data}

Data on the skilled population aged 25 and more (proxy of the skilled labor force) are computed following Docquier and Marfouk (2006). De la Fuente and Domenech is used for OECD countries and Barro and Lee (2000) data for other countries. For countries where Barro and Lee measures are missing, Cohen and Soto's available indicators (2001) are used or the skill sharing of the neighbouring country with the closest rate of enrollment in education are transposed. For migration data we used US immigration data by educational attainment and by country of birth (source US census). Table 1 provides some descriptive statistics of the main variables.

Table 1: Descriptive statistics

\begin{tabular}{l|ccccc}
\hline Variable & Obs & Mean & Std. Dev. & Min & Max \\
\hline & & & & & \\
Proximity & 368 & -1.695461 & .9239974 & -4.384035 & -.0496259 \\
Fraction & 368 & .0716159 & .0745554 & 0.001 & .4802 \\
Skilled emigration (logs) & 368 & 8.619314 & 2.536431 & 0 & 13.34147 \\
Proximity*emigration & 368 & -13.60918 & 7.751697 & -36.35066 & 0 \\
Proximity*fraction & 368 & -.0785127 & .0727859 & -.4382261 & -.0025862 \\
\hline
\end{tabular}




\subsection{Empirical specification}

Following VAM, we consider the following augmented empirical specification, where we add the direct and composite effect for migration on TFP growth:

$$
\begin{aligned}
g_{i, t}= & \alpha_{0}+\alpha_{1} a_{i, t-1}+\alpha_{2} h_{i, t-1}+\alpha_{3} \operatorname{logmig}_{i, t-1}+ \\
& +\alpha_{4} a_{i, t-1} * h_{i, t-1}+\alpha_{5} a_{i, t-1} * \operatorname{logmig}_{i, t-1}+\epsilon_{i, t}
\end{aligned}
$$

where $g_{i, t}=\log A_{i, t}-\log A_{i, t-1}, A_{i, t}$ being TFP in country $i$ at period $t$, $a_{i, t-1} \equiv \log A_{i, t-1}-\log \bar{A}_{t-1}$ is the $\log$ of the proximity to the total factor productivity frontier in the previous period (this last variable is a negative number), $h_{i, t-1}$ is the fraction of the population with higher education in the previous period (i.e. stock of tertiary educated worker divided by the total stock of population worker), $\operatorname{logmig}_{i, t-1}$ is the log of tertiary educated migrants to the US +1 , to avoid missing values, $\alpha_{0}$ reflects country dummies which control for unobserved country fixed effects in TFP growth. All the regressions are run with time dummies to control for common shocks. In addition to the country fixed effect, we consider $a_{i, t-1}$ and its interaction terms as endogenous. By construction, in fact, proximity to the frontier, $a_{i, t-1}$, is correlated with the lags of the dependent variable. We treat the lagged skilled emigration stock (in logs) and the fraction of skilled workers as sequentially exogenous variables. ${ }^{19}$ We use as excluded instruments the $\log$ of proximity lagged two periods, $a_{i, t-2}$, the lagged two periods values of the fraction of human capital and of the log of skilled emigrants, the interacted terms lagged two periods. ${ }^{20}$ In order to test the relevance of the instruments we consider some tests and statistics from the first stage regression. Finally, we correct for heteroskedasticity, considering robust standard

\footnotetext{
${ }^{19}$ We consider the log of skilled emigration and the fraction of human capital as sequentially exogenous, i.e. the error term is uncorrelated with current and past values of the independent variables. As the log of skilled emigration (lagged) is a stock measure we think that can be treated as exogenous. (In the contest of an overidentified model, given the fraction of human capital as exogenous, we consider a "C test" or "differencein-Sargan" test, that suggests us to treat it as exogenous) Moreover, on the contrary than in Vandebussche, Aghion and Costa Meghir, here the fraction of human capital is also exogenous. In the contest of an overidentified model, given the log of skilled migration as exogenous, we consider a "C test" or "difference-in-Sargan" test, that suggests us to treat human capital as exogenous.

${ }^{20}$ The choice of lagging twice is the result of trying to eliminate as much endogeneity as possible, but at the same time not going too far back in time to preserve observations for the empirical analysis, given the small data set that we have
} 
errors in a GMM framework. ${ }^{21}$ The estimation method is GMM method on within group since we take out the country effects, i.e. a LSDV method, that we know it can produce downward biased estimates in small sample (Nickell bias, 1981). However in this context we believe that the within estimator is the most appropriate one. As VAM suggest, "even if it is well known that within groups is biased in panels with a low time dimension, the first difference estimator would lead to much greater biases, because the instruments are not capable of predicting the first difference in the education and distance"'. Moreover it has been recently shown ${ }^{22}$ that, when $\mathrm{T}$ is small, and there are highly persistent series, then even the first different estimator, such as the Arellano-Bond estimator, is downward biased. Second, even if the system GMM shows to have better small sample performance, according to Islam (2003), the LSDV shows very good performance too in growth converging equation, despite the well known Nickell bias. ${ }^{23}$ And again, Acemoglue, Aghion and Zilibotti (2003), who use a within extimator in the same context, maintain that "estimates that use additional moment restrictions can improve efficiency, though they may have undesiderable small sample properties"'.

\subsection{Estimation results}

\section{First stage regression}

The estimation results for our first stage regression are represented in table 2. All the regressions are run with time dummies and country dummies. The excluded instruments are the log of proximity lagged twice (i.e. 10 years before), the lagged two periods values both of the fraction of human capital and the log of skilled migrants, the two interacted terms lagged two periods. The included instruments are the fraction of tertiary educated workers lagged one period and the log of tertiary migrants lagged one period. In the first reduced form for the log of distance to the frontier in the previous period, its lagged values is highly significant. In the second reduced form for the interacted variable that refers to migration we find that almost all of the excluded instruments are highly significant (except the log of proximity lagged twice). Finally, for the interacted variable that refers to skilled workers,

\footnotetext{
${ }^{21}$ Serial correlation is ruled out when country dummies are included in the regressions

${ }^{22}$ see Islam (2003b) for a discussion

${ }^{23} \mathrm{He}$ provides Monte Carlo Simulation with data from the PWT
} 
Table 2: First stage regression

\begin{tabular}{|c|c|c|c|}
\hline & $\overline{a_{i, t-1}}$ & $\bar{a}_{i, t-1} * l m i g_{i, t-1}$ & $a_{i, t-1} * h_{i, t-1}$ \\
\hline$h_{i, t-1}$ & $\begin{array}{c}1.61260^{* *} \\
(0.72530)\end{array}$ & $\begin{array}{c}15.679^{* *} \\
(6.528)\end{array}$ & $\begin{array}{c}-1.217^{* * *} \\
(0.132)\end{array}$ \\
\hline lagged $h_{i, t-1}$ & $\begin{array}{c}-1.95877^{*} \\
(1.05145)\end{array}$ & $\begin{array}{c}-25.165^{\text {*** }} \\
(8.761)\end{array}$ & $\begin{array}{c}0.884^{* * *} \\
(0.216)\end{array}$ \\
\hline $\operatorname{logmig}_{i, t-1}$ & $\begin{array}{c}-0.03840 \\
(0.028)\end{array}$ & $\begin{array}{c}-3.001^{* * *} \\
(0.124)\end{array}$ & $\begin{array}{l}-0.004 \\
(0.003)\end{array}$ \\
\hline lagged $\operatorname{logmig}_{i, t-1}$ & $\begin{array}{c}-0.01544 \\
(0.04342)\end{array}$ & $\begin{array}{c}1.467^{* * *} \\
(0.351)\end{array}$ & $\begin{array}{l}0.005 \\
(0.004)\end{array}$ \\
\hline lagged $a_{i, t-1}$ & $\begin{array}{c}0.71821^{* * *} \\
(0.26522)\end{array}$ & $\begin{array}{l}0.478 \\
(1.594)\end{array}$ & $\begin{array}{l}-0.022 \\
(0.015)\end{array}$ \\
\hline lagged $a_{i, t-1} * h_{i, t-1}$ & $\begin{array}{c}-0.84538 \\
(0.60780)\end{array}$ & $\begin{array}{c}-12.086^{* *} \\
(4.846)\end{array}$ & $\begin{array}{c}0.711^{\text {*** }} \\
(0.119)\end{array}$ \\
\hline lagged $a_{i, t-1} * \operatorname{lmig}_{i, t-1}$ & $\begin{array}{l}-0.018 \\
(0.026)\end{array}$ & $\begin{array}{c}0.498^{* * *} \\
(0.185)\end{array}$ & $\begin{array}{l}0.003 \\
(0.002)\end{array}$ \\
\hline Intercept & $\begin{array}{l}-1.236 \\
(0.783)\end{array}$ & $\begin{array}{l}-1.328 \\
(4.796)\end{array}$ & $\begin{array}{c}-0.072^{*} \\
(0.043)\end{array}$ \\
\hline$d 95$ & $\begin{array}{l}-0.011 \\
(0.020)\end{array}$ & $\begin{array}{l}-0.020 \\
(0.154)\end{array}$ & $\begin{array}{l}0.000 \\
(0.003)\end{array}$ \\
\hline$d 00$ & $\begin{array}{l}-0.036 \\
(0.032)\end{array}$ & $\begin{array}{l}-0.204 \\
(0.235)\end{array}$ & $\begin{array}{l}0.002 \\
(0.004)\end{array}$ \\
\hline country dummies & yes & yes & yes \\
\hline $\mathrm{N}$ & 276 & 276 & 276 \\
\hline $\begin{array}{l}\text { Partial } \mathrm{R}^{2} \text { of excl. instr. } \\
\text { Test of excl.instr.: }\end{array}$ & 0.25 & 0.3065 & 0.537 \\
\hline $\begin{array}{l}\mathrm{F}_{(5,175)} \\
\mathrm{Prob}>\mathrm{F}\end{array}$ & $\begin{array}{l}7.18 \\
0.000\end{array}$ & $\begin{array}{l}12.08 \\
0000\end{array}$ & $\begin{array}{l}17.84 \\
0000\end{array}$ \\
\hline
\end{tabular}

Note: Robust Standard Errors in parentheses. Country dummies are not reported. A test for the joint significance of country dummies yields a $\mathrm{P}$-value of $0 . * * *$ and *** indicate significance at 10,5,1 percent level respectively 
both its lagged value and the lagged (twice) fraction of human capital are significant instruments. Moreover, our instruments have jointly explanatory power.

The estimates Following VAM, we start with pure level regressions, without interaction terms. ${ }^{24}$ We consider at first only variables related to human capital, later on we add variables who refer to migration. In all the specifications, the lagged distance to the frontier, the catch-up term, is always negative, as predicted by the theory (i.e. the further away from the frontier, the faster a country will catch-up). In table (3), the effect of the lagged distance on growth, implying TFP convergence not mediated by education, is significant only when the country effects are included. In table (4), when we consider also the effect of migration on TFP growth, when the interaction effect between skilled emigration and proximity to the frontier is included, the catch up term, not mediated either by education or by emigration, turns out to be not significant (models (7) and (8)).

The effect of the fraction of tertiary educated workers on TFP growth is positive, meaning that human capital is important for innovation. In our estimations, from model (1) to model (7) this effect is not very significant (10\% in models (3) (7)), but when we include in the model both the interaction effect between proximity and skilled emigration and country fixed effect, the estimated coefficient turns out to be higher and statistically significant at $5 \%$.

The interaction effect between proximity and the proportion of workers with tertiary education is positive (as VAM), meaning that skilled workers are more important for growth in economies closer to the frontier, or see in another way "for countries with higher levels of skilled workers the lagged effect of proximity to the frontier on growth is less negative". ${ }^{25}$ When we do not consider any effect on TFP growth mediated by migration, the interaction effect between proximity and the proportion of skilled workers, excluding country dummies, is positive (0.215) and statistically significant at $5 \%$ but when we include country dummies it turns out to be insignificant. When we estimate our model considering also migration variables, its coefficient is still positive but statistically significant at $10 \%$ (when we include country

\footnotetext{
${ }^{24}$ We follow VAM, even if our analysis is a simplified one. Moreover, our sample includes also no-OECD countries. Therefore data quality and availability is worst than for only OECD countries. (The instruments used for education also are different. They used education expenditure, that is not available for no-OECD countries)

${ }^{25}$ Aghion et al. (2006)
} 
dummies).

The interaction effect between proximity and the log of skilled emigrants is negative, implying that skilled emigration has a decreasing effect on growth when a country approaches to the frontier, or see in another way, skilled migration seems to be more important for countries far from the frontier. This effect is very significant with a coefficient equal to -0.055 , when we allow for country dummies (otherwise it is not significant). The direct effect of migration on TFP growth has a positive sign from model (5) to (7), but the sign changes when the interaction effect between migration and proximity is introduced.

Robustness on empirical results. From the previous empirical analysis some implications emerge: skilled human capital has a higher growing effect closer to technological frontier, on the contrary skilled migration is more important for countries far from the frontier.

We would like now to check for non linearities and to examine how skilled migration can have a different impact on TFP growth according to the different characteristics of the countries. As we explained in section 2, some countries gain from migration, other countries not. What is it important? The level of development of a country? Its size? We consider the World Bank classification among countries, dividing the sample into high income countries, high middle income countries, low middle income countries and low income countries. We rule out from the sample countries classified as low income countries. If we look at the composite effects between migration (human capital) and distance to the frontier, results from our full specification are confirmed. Now the magnitude of the coefficients of the interaction terms are higher and their effects are both statistically significant at 5 percent. On the contrary, if we exclude high income countries from the sample, all the signs of the coefficients are preserved from our full sample results, but the only significant variable (at 10 percent) is the interaction effect between migration and distance to the frontier This seems to confirm that for countries closer to the frontier, skilled human capital has a higher growth-enhancing effect, and migration as a larger negative impact on growth (and conversely).

We want now to allow for non linearities respect to the distance to the frontier, $a$. We consider two country groups, one group with countries "far from the frontier" and the other one (the reference (omitted) group) with countries closer to the frontier. In order to do so, we create a dummy variable for 
the group "far from the frontier", choosing a threshold level for proximity. ${ }^{26}$ Then we generate four variables that are the product of the dummy variable and our explanatory variables (except proximity). We consider five different proximity thresholds $(-3.183871-2.56344-2.536362-2.089547-1.695461)$, to see how our estimations change. Focusing on migration, we can see from the results that for the interaction term between proximity and migration, under a certain level of distance to the frontier, migration has a positive effect on growth (when the threshold is around -2.50), but then it turns out to be negative when countries are very far from the frontier. A plausible explanation can be that adoption related to migration is relevant only if the country has reached a minimum level of development. Countries really poor benefit less from migration externalities.

As far as the size of the country is concerned, we would expect that the size matters: large countries have larger diasporas and therefore larger networks, intuitively large countries are more likely to benefit from the diaspora. We consider the country size classification as in Docquier and Marfouk (2005). We create two country groups, one group with large size population (with population above 25 million) and the other one (the reference (omitted) group) with population below 25 million. Hence, we create a dummy variable for the group with large population and we generate four variables that are the product of the dummy variable and our explanatory variables. We do not see any statistically significant difference between the two groups. We consider also two country samples, one without large size countries, the other without small size countries. In this second group, the magnitude of the interaction coefficient between the distance to the frontier and migration is now higher than in the full sample model, but significant at $10 \%$. If we exclude large size countries, we do not have any significant change from the full sample model. The size of the country per se does not seem to be so important.

\section{Conclusion}

Skilled emigrants can have an important role in the transfer of knowledge and technology from the most to the less developed world through more

\footnotetext{
${ }^{26}$ i.e. the dummy is equal to one when the proximity is less than (or equal to) the proximity threshold
} 
or less informal networks. Therefore, even if the loss of human capital can slow down the growth process, the source economy can still benefit from the stimulation of growth through imitation and knowledge diffusion. To investigate the impact of skilled migration on growth due to network externalities, we consider a previous work by Vandebussche, Aghion and Costa Meghir (2006), in which they examine the contribution of human capital to economic growth, where technological improvements are a result of a combination between innovation and imitation (adoption), a specification that they share with Benhabib and Spiegel (1994), Acemoglue Aghion and Zilibotti (2006). Considering that both activities, i.e. imitation and innovation, make use of both high skilled and unskilled labor, Vandebussche, Aghion and Costa Meghir find that skilled labor has a higher growth enhancing impact closer to the technological frontier (and conversely the growth-enhancing effect of unskilled human capital decreases with the proximity to the frontier), given the assumption that innovation makes a relative more intensive use of skilled labor. Extending this model and allowing for a positive effect of migration on adoption, we show that a marginal increase in the stock of skilled human capital contributes more to productivity growth if a state is closer to technological frontier (and vice versa) and consequently migration should raise growth in area far from the frontier. We provide evidence in favor of this prediction by using a panel data set covering 92 countries between 1980 and 2000. In accordance to the stylized fact we allow for non linearities, trying to understand if the level of development and/or the home country size are key factors to have a successful diaspora. Adoption through migration seems to be more relevant the farther the country is from the frontier, even if it is necessary that the country has reached a minimum level of development to have a positive and significant effect. From our estimation the size of the country per se does not seem to be relevant. 
Table 3: Tfp growth equation

\begin{tabular}{lcccc}
\hline \hline & $\mathbf{( 1 )}$ & $\mathbf{( 2 )}$ & $\mathbf{( 3 )}$ & $\mathbf{( 4 )}$ \\
\hline Proximity & -0.012 & $-0.731^{* * *}$ & -0.016 & $-0.760^{* * *}$ \\
& $(0.014)$ & $(0.142)$ & $(0.013)$ & $(0.148)$ \\
Fraction & 0.149 & 0.168 & $0.281^{*}$ & 0.942 \\
& $(0.137)$ & $(0.482)$ & $(0.144)$ & $(0.714)$ \\
Proximity*fraction & & & $0.215^{* *}$ & 0.641 \\
& & & $(0.098)$ & $(0.467)$ \\
d95 & -0.010 & $-0.041^{* *}$ & -0.005 & $-0.042^{* *}$ \\
& $(0.020)$ & $(0.017)$ & $(0.019)$ & $(0.017)$ \\
d00 & $0.032^{*}$ & -0.032 & $0.038^{* *}$ & -0.032 \\
& $(0.018)$ & $(0.026)$ & $(0.017)$ & $(0.027)$ \\
Intercept & -0.015 & 0.018 & -0.018 & -0.102 \\
& $(0.031)$ & $(0.085)$ & $(0.030)$ & $(0.119)$ \\
country dummies & no & yes & no & yes \\
\hline Anderson canon. corr. LR stat. & 776.290 & 76.054 & 899.19 & 81.414 \\
(identif./IV relev. test) & & & & \\
Chi-sq(.) P-value & 0.000 & 0.000 & 0.000 & 0.000 \\
Hansen J stat. & eq. ex. & eq. ex. & 0.302 & 0.939 \\
(overid. test of all instr.) & ident. & ident. & & \\
Chi-sq(.) P-value & & & 0.583 & 0.333 \\
\hline \hline N & 276 & 276 & 276 & 276 \\
$\mathrm{R}^{2}$ & 0.03 & 0.69 & 0.041 & 0.69 \\
\hline
\end{tabular}


Table 4: Tfp growth equation

\begin{tabular}{|c|c|c|c|c|}
\hline & $\overline{(5)}$ & 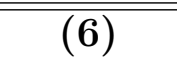 & 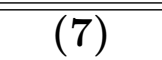 & (8) \\
\hline Proximity & $\begin{array}{c}-0.028^{*} \\
(0.014)\end{array}$ & $\begin{array}{c}-0.738^{* * *} \\
(0.149)\end{array}$ & $\begin{array}{l}-0.019 \\
(0.039)\end{array}$ & $\begin{array}{l}-0.285 \\
(0.230)\end{array}$ \\
\hline Fraction & $\begin{array}{l}0.238 \\
(0.147)\end{array}$ & $\begin{array}{l}1.168 \\
(0.715)\end{array}$ & $\begin{array}{l}0.266^{*} \\
(0.138)\end{array}$ & $\begin{array}{c}1.436^{* *} \\
(0.707)\end{array}$ \\
\hline Skilled emigration (logs) & $\begin{array}{c}0.012^{* * *} \\
(0.003)\end{array}$ & $\begin{array}{c}0.034^{* *} \\
(0.016)\end{array}$ & $\begin{array}{c}0.009 \\
(0.010)\end{array}$ & $\begin{array}{c}-0.103^{*} \\
(0.052)\end{array}$ \\
\hline Proximity*fraction & $\begin{array}{c}0.331^{* * *} \\
(0.104)\end{array}$ & $\begin{array}{l}0.819^{*} \\
(0.475)\end{array}$ & $\begin{array}{c}0.346^{* * *} \\
(0.112)\end{array}$ & $\begin{array}{l}0.878^{*} \\
(0.476)\end{array}$ \\
\hline Proximity*emigration & & & $\begin{array}{l}-0.001 \\
(0.004)\end{array}$ & $\begin{array}{c}-0.055^{* * *} \\
(0.020)\end{array}$ \\
\hline $\mathrm{d} 95$ & $\begin{array}{l}-0.006 \\
(0.019)\end{array}$ & $\begin{array}{c}-0.051^{* * *} \\
(0.017)\end{array}$ & $\begin{array}{l}-0.001 \\
(0.019)\end{array}$ & $\begin{array}{c}-0.037^{* *} \\
(0.018)\end{array}$ \\
\hline $\mathrm{d} 00$ & $\begin{array}{c}0.035^{* *} \\
(0.017)\end{array}$ & $\begin{array}{c}-0.051^{* *} \\
(0.025)\end{array}$ & $\begin{array}{c}0.038^{* *} \\
(0.017)\end{array}$ & $\begin{array}{l}-0.031 \\
(0.026)\end{array}$ \\
\hline Intercept & $\begin{array}{c}-0.129^{* * *} \\
(0.050)\end{array}$ & $\begin{array}{c}-0.983^{* * *} \\
(0.351)\end{array}$ & $\begin{array}{l}-0.105 \\
(0.099)\end{array}$ & $\begin{array}{l}0.586 \\
(0.657)\end{array}$ \\
\hline country dummies & no & yes & no & yes \\
\hline $\begin{array}{l}\text { Anderson canon. corr. LR stat. } \\
\text { (identif./IV relev. test) }\end{array}$ & 896.973 & 75.936 & 779.38 & 76.847 \\
\hline Chi-sq(.) P-value & 0.000 & 0.000 & 0.000 & 0.000 \\
\hline $\begin{array}{l}\text { Hansen J stat. } \\
\text { (overid. test of all instr.) }\end{array}$ & 0.245 & 0.559 & 2.512 & 0.961 \\
\hline Chi-sq(.) P-value & 0.6205 & 0.4547 & 0.2847 & 0.6185 \\
\hline $\mathrm{N}$ & 276 & 276 & 276 & 276 \\
\hline $\mathrm{R}^{2}$ & 0.083 & 0.69 & 0.08 & 0.69 \\
\hline
\end{tabular}


Table 5: Tfp growth equation

\begin{tabular}{|c|c|c|}
\hline & $\begin{array}{c}\text { sample without } \\
\text { low-income countries }\end{array}$ & $\begin{array}{c}\text { sample without } \\
\text { high-income countries }\end{array}$ \\
\hline Proximity & $\begin{array}{c}0.035 \\
(0.471)\end{array}$ & $\begin{array}{c}-0.313 \\
(0.251)\end{array}$ \\
\hline Fraction & $\begin{array}{l}2.256^{*} \\
(1.178)\end{array}$ & $\begin{array}{l}0.485 \\
(1.599)\end{array}$ \\
\hline Skilled emigration $(\operatorname{logs})$ & $\begin{array}{c}-0.158^{* * *} \\
(0.058)\end{array}$ & $\begin{array}{r}-0.096 \\
(0.080)\end{array}$ \\
\hline Proximity*fraction & $\begin{array}{c}1.894^{* *} \\
(0.801)\end{array}$ & $\begin{array}{l}0.312 \\
(0.978)\end{array}$ \\
\hline Proximity*emigration & $\begin{array}{c}-0.117^{* *} \\
(0.052)\end{array}$ & $\begin{array}{r}-0.053^{*} \\
(0.030)\end{array}$ \\
\hline d95 & $\begin{array}{l}-0.021 \\
(0.022)\end{array}$ & $\begin{array}{r}-0.041^{*} \\
(0.022)\end{array}$ \\
\hline d00 & $\begin{array}{l}-0.029 \\
(0.033)\end{array}$ & $\begin{array}{l}-0.040 \\
(0.031)\end{array}$ \\
\hline Intercept & $\begin{array}{l}-1.140 \\
(1.138)\end{array}$ & $\begin{array}{r}-1.643^{*} \\
(0.860)\end{array}$ \\
\hline country dummies & yes & yes \\
\hline $\begin{array}{l}\text { Anderson canon. corr. LR stat. } \\
\text { (identif./IV relev. test) }\end{array}$ & 58.701 & 55.702 \\
\hline Chi-sq(3) P-value & 0.000 & 0.000 \\
\hline $\begin{array}{l}\text { Hansen J stat. } \\
\text { (overid. test of all instr.) }\end{array}$ & 4.050 & 1.625 \\
\hline Chi-sq(2) P-value & 0.1320 & 0.4437 \\
\hline N & 186 & 2222 \\
\hline $\mathrm{R}^{2}$ & 0.700 & 0.691 \\
\hline
\end{tabular}


Table 6: Tfp growth equation

\begin{tabular}{|c|c|c|c|c|c|}
\hline & $(1)$ & $(2)$ & $\overline{(3)}$ & $(4)$ & $(5)$ \\
\hline Proximity & $\begin{array}{l}-0.327 \\
(0.217)\end{array}$ & $\begin{array}{l}-0.279 \\
(0.207)\end{array}$ & $\begin{array}{l}-0.276 \\
(0.206)\end{array}$ & $\begin{array}{l}-0.235 \\
(0.194)\end{array}$ & $\begin{array}{l}-0.210 \\
(0.215)\end{array}$ \\
\hline Fraction & $\begin{array}{l}1.474^{*} \\
(0.763)\end{array}$ & $\begin{array}{c}2.682^{* * *} \\
(0.784)\end{array}$ & $\begin{array}{c}2.698^{* * *} \\
(0.785)\end{array}$ & $\begin{array}{c}2.607^{* * *} \\
(0.940)\end{array}$ & $\begin{array}{l}1.926^{*} \\
(0.983)\end{array}$ \\
\hline Fraction* $d_{\text {highdist }}$ & $\begin{array}{c}-9.846 \\
(66.538)\end{array}$ & $\begin{array}{l}-83.073 \\
(54.636)\end{array}$ & $\begin{array}{l}-72.023 \\
(66.021)\end{array}$ & $\begin{array}{l}-21.071 \\
(14.860)\end{array}$ & $\begin{array}{l}-2.304 \\
(5.098)\end{array}$ \\
\hline Skilled emigration (logs) & $\begin{array}{c}-0.090^{*} \\
(0.051)\end{array}$ & $\begin{array}{c}-0.114^{* *} \\
(0.053)\end{array}$ & $\begin{array}{c}-0.117^{* *} \\
(0.052)\end{array}$ & $\begin{array}{c}-0.137^{* * *} \\
(0.051)\end{array}$ & $\begin{array}{c}-0.134^{* * *} \\
(0.049)\end{array}$ \\
\hline Skilled emigration $(\operatorname{logs})^{*} d_{\text {highdist }}$ & $\begin{array}{c}0.069 \\
(0.274)\end{array}$ & $\begin{array}{c}0.353^{* *} \\
(0.172)\end{array}$ & $\begin{array}{c}0.316 \\
(0.200)\end{array}$ & $\begin{array}{c}0.129^{* *} \\
(0.064)\end{array}$ & $\begin{array}{l}0.075 \\
(0.055)\end{array}$ \\
\hline Proximity*fraction & $\begin{array}{l}0.880^{*} \\
(0.505)\end{array}$ & $\begin{array}{c}1.608^{* * *} \\
(0.510)\end{array}$ & $\begin{array}{c}1.625^{* * *} \\
(0.524)\end{array}$ & $\begin{array}{c}1.955^{* * *} \\
(0.710)\end{array}$ & $\begin{array}{l}1.491^{*} \\
(0.851)\end{array}$ \\
\hline Proximity*fraction $* d_{\text {highdist }}$ & $\begin{array}{c}-3.733 \\
(22.144)\end{array}$ & $\begin{array}{r}-33.864^{*} \\
(19.266)\end{array}$ & $\begin{array}{l}-30.227 \\
(22.334)\end{array}$ & $\begin{array}{l}-9.795 \\
(6.929)\end{array}$ & $\begin{array}{l}-1.256 \\
(2.707)\end{array}$ \\
\hline Proximity*emigration & $\begin{array}{c}-0.050^{* *} \\
(0.020)\end{array}$ & $\begin{array}{l}-0.076 \\
(0.021)\end{array}$ & $\begin{array}{c}-0.077^{* * *} \\
(0.022)\end{array}$ & $\begin{array}{c}-0.083^{* * *} \\
(0.022)\end{array}$ & $\begin{array}{c}-0.083^{* * *} \\
(0.023)\end{array}$ \\
\hline Proximity*emigration* $d_{\text {highdist }}$ & $\begin{array}{c}0.022 \\
(0.087)\end{array}$ & $\begin{array}{c}0.141^{* *} \\
(0.062)\end{array}$ & $\begin{array}{l}0.129^{*} \\
(0.072)\end{array}$ & $\begin{array}{c}0.061^{* *} \\
(0.031)\end{array}$ & $\begin{array}{l}0.041 \\
(0.029)\end{array}$ \\
\hline Intercept & $\begin{array}{l}0.416 \\
(0.664)\end{array}$ & $\begin{array}{c}0.212 \\
(0.687)\end{array}$ & $\begin{array}{c}0.253 \\
(0.667)\end{array}$ & $\begin{array}{c}0.556 \\
(0.703)\end{array}$ & $\begin{array}{l}0.773 \\
(0.696)\end{array}$ \\
\hline $\begin{array}{l}\text { country dummies } \\
\text { time dummies }\end{array}$ & $\begin{array}{l}\text { yes } \\
\text { yes }\end{array}$ & $\begin{array}{l}\text { yes } \\
\text { yes }\end{array}$ & $\begin{array}{l}\text { yes } \\
\text { yes }\end{array}$ & $\begin{array}{l}\text { yes } \\
\text { yes }\end{array}$ & $\begin{array}{l}\text { yes } \\
\text { yes }\end{array}$ \\
\hline Proximity threshold & -3.18 & -2.56 & -2.54 & -2.09 & -1.69 \\
\hline $\begin{array}{l}\text { Anderson canon. corr. LR stat. } \\
\text { (identif./IV relev. test) }\end{array}$ & 43.545 & 39.352 & 25.234 & 58.801 & 63.688 \\
\hline Chi-sq(5) P-value & 0.0000 & 0.0000 & 0.0001 & 0.0000 & 0.0000 \\
\hline $\begin{array}{l}\text { Hansen J stat. } \\
\text { (overid. test of all instr.) }\end{array}$ & 2.013 & 1.942 & 1.838 & 5.300 & 3.477 \\
\hline Chi-sq(4) P-value & 0.7333 & 0.7464 & 0.7655 & 0.2579 & 0.4813 \\
\hline $\mathrm{N}$ & 276 & 276 & 276 & 276 & 276 \\
\hline $\mathrm{R}^{2}$ & 0.695 & 0.7053 & 0.702 & 0.702 & 0.701 \\
\hline
\end{tabular}


Table 7: Tfp growth equation

\begin{tabular}{lcc}
\hline \hline & $\begin{array}{c}\text { sample without } \\
\text { large size country }\end{array}$ & $\begin{array}{c}\text { sample without } \\
\text { small size country }\end{array}$ \\
\hline Proximity & $-0.401^{*}$ & -0.043 \\
& $(0.242)$ & $(0.365)$ \\
Fraction & $1.862^{* *}$ & $1.916^{* *}$ \\
& $(0.868)$ & $(0.870)$ \\
Skilled emigration (logs) & $-0.104^{*}$ & -0.096 \\
& $(0.061)$ & $0.073)$ \\
Proximity*fraction & $1.105^{*}$ & $0.963^{*}$ \\
& $(0.585)$ & $(0.509)$ \\
Proximity*emigration & $-0.054^{* *}$ & $-0.067^{*}$ \\
& $(0.023)$ & $(0.035)$ \\
d95 & $-0.050^{* *}$ & $-0.041^{*}$ \\
d00 & $(0.020)$ & $(0.021)$ \\
& -0.038 & -0.051 \\
Intercept & $(0.027)$ & $(0.032)$ \\
& $-1.156^{*}$ & -0.810 \\
country dummies & $(0.663)$ & $(1.088)$ \\
\hline Anderson canon. corr. LR stat. & yes & yes \\
(identif./IV relev. test) & 42.499 & 61.792 \\
Chi-sq(.) P-value & & \\
Hansen J stat. & 0.000 & 0.0000 \\
(overid. test of all instr.) & 0.598 & 0.861 \\
Chi-sq(.) P-value & & \\
\hline \hline N & 0.7417 & 0.6502 \\
\hline
\end{tabular}


Table 8: Tfp growth equation

\begin{tabular}{lc}
\hline Proximity & $-0.496^{* *}$ \\
& $(0.210)$ \\
Fraction & $1.958^{* *}$ \\
& $(0.868)$ \\
Fraction*large & -1.496 \\
& $(1.249)$ \\
Skilled emigration (logs) & -0.092 \\
& $(0.057)$ \\
Skilled emigration (logs)*large & 0.148 \\
& $(0.105)$ \\
Proximity*fraction & $1.090^{*}$ \\
& $(0.587)$ \\
Proximity*fraction*large & -0.707 \\
& $(1.176)$ \\
Proximity*emigration & $-0.048^{* *}$ \\
& $(0.022)$ \\
Proximity*emigration*large & 0.049 \\
R & $(0.030)$ \\
Intercept & -0.936 \\
country dummies & $(1.237)$ \\
time dummies & yes \\
Anderson canon. corr. LR stat. & 61.715 \\
\hline \hline & \\
Chidentif./IV relev. test) & 0.0000 \\
\hline & 5.162 \\
& \\
&
\end{tabular}




\section{Appendix}

\subsection{An extension of the model}

In Section 3, we assume that unskilled workers are immobile, i.e. $M_{u, t}=0$. As the aim of our study is to investigate the relationship between growth and the importance of the skilled diaspora in the transfer of idea, we don't want to test the role of unskilled migrants on growth. Yet, one might think that, by affecting the relative productivity of the two activities, innovation and imitation, unskilled migration could also have an effect on growth, even if it might not induce spillover effects. In this appendix we discuss the implication of unskilled migration in our model.

Recalling section 3.1, now, after migration, the fraction of skilled workers $s$ in the economy, at time $t$, is given by:

$$
s_{t} \equiv \frac{\bar{S}-M_{s, t}}{\bar{S}+\bar{U}-M_{s, t}-M_{u, t}}=\frac{\bar{S}-M_{s, t}}{N-M_{s, t}-M_{u, t}}
$$

whereas the fraction of unskilled workers is given by:

$$
u_{t} \equiv \frac{\bar{U}-M_{u, t}}{\bar{S}+\bar{U}-M_{s, t}-M_{u, t}}=\frac{N-\bar{S}-M_{u, t}}{N-M_{s, t}-M_{u, t}}
$$

Recalling section 3.3, and in particular equatiion (19), we have an additional impact of migration on the growth rate, due to unskilled migration. ${ }^{27}$ In fact, now we have a further effect:

$$
\frac{1}{\gamma} \frac{d g}{d M_{u}}=\frac{\partial g}{\partial s} \frac{\partial s}{\partial M_{u}}
$$

where:

$$
\frac{\partial s}{\partial M_{u}}=\frac{\bar{S}-M_{s, t}}{\left(\bar{S}+\bar{U}-M_{s, t}-M_{u, t}\right)^{2}}
$$

\footnotetext{
${ }^{27}$ here we don't discuss the impact of skilled migation on growth as it is the same as in the case without unskilled migration. The only difference is that equation (22) now is given by $\frac{d s}{d M_{s}}=\frac{-\left(\bar{U}-M_{u}\right)}{\left(\bar{S}+\bar{U}-M_{s}-M_{u}\right)^{2}}$ that is always negative as before, given that $\left.\bar{U}-M_{u}\right)>0$
} 
that is always positive (given that the number of skilled workers at home is positive after migration, $\bar{S}-M_{s, t}>0$ ), reflecting the fact that unskilled migration increases the fraction of skilled labor. ${ }^{28}$ As in the previous case, we have:

$$
\frac{\partial g}{\partial s}=-\phi h\left(a, M_{s}\right)^{1-\phi}+(1-\phi) h\left(a, M_{s}\right)^{-\phi}
$$

that has an ambiguous effect on the growth rate. In fact it will be positive only if $\frac{1-\phi}{\phi}>h\left(a, M_{s}\right)$, i.e. given $h$, if the elasticity of skilled labor in innovation is high enough. Therefore, remembering that $h$ is a decreasing function in $a$, far from the frontier, an increase in $s$ will be growth enhancing only if the induced amount of innovation is enough to compensate for the loss in imitation. Moreover,

$$
\left(\frac{\partial g}{\partial s}\right) \frac{\partial}{\partial a}=\left[-\phi(1-\phi) h\left(a, M_{s}\right)^{-\phi}-\phi(1-\phi) h\left(a, M_{s}\right)^{-(1+\phi)}\right] \frac{\partial h\left(a, M_{s}\right)}{\partial a}
$$

that is always positive, as $h$ is a decreasing function in $a$, showing the complementarity between $s$ and $a$.

We can now discuss the implications given by unskilled migration on growth:

- If skilled labor induces a negative effect on growth, i.e. $\frac{\partial g}{\partial s}<0$ (that is likely the far the country is from the frontier), unskilled migration has a negative impact on growth, $\frac{1}{\gamma} \frac{d g}{d M_{u}}<0$ and this is intuitively as unskilled migration rises the fraction of skilled workers in the country. At the same time skilled migration has a positive effect on growth (both for the spillover effects and the negative effect on the fraction of skilled labour in the country)

- If skilled labor is growth enhancing, $\frac{\partial g}{\partial s}>0$, (that it is more likely when country is closer to the frontier), unskilled migration has a positive impact on growth, $\frac{1}{\gamma} \frac{d g}{d M_{u}}>0$ also here for the fact that unskilled

\footnotetext{
${ }^{28}$ Considering the relative factor intensities in imitation and innovation given by $\frac{u_{m, t}}{s_{m, t}}=$ $\frac{\Psi}{h\left(a_{t-1}, M_{s, t}\right)}$ and $\frac{u_{n, t}}{s_{n, t}}=\frac{1}{h\left(a_{t-1}, M_{s, t}\right)}$, we have that an increase in $s$ leads to an increase in the amount of units of labor, both skilled and unskilled, used in innovation (activities that employed skilled labor more intensively) and to a corresponding decrease in labor input in imitation. Therefore an increase in unskilled migration will induce an increase in s and therefore a reallocation of labor inputs towards innovation
} 
migration rises the fraction of skilled workers in the country, $\frac{d s}{d M_{u}}>0$. On the other side, two opposite effects on productivity growth will arise due to skilled migration: a growth enhancing effect due to the role of migrants in transferring technology from abroad (that will be smaller the higher is $a$ ), a growth decreasing effect induced by the loss of skilled labour.

\subsection{Country classification}

By income group. HIGH INCOME: Andorra, Australia, Austria, The Bahamas, Belgium, Brunei Darussalam, Canada, Cyprus, Denmark, Finland, France, Germany, Greece, Hong Kong (China), Iceland, Ireland, Israel, Italy, Japan, Kuwait, Liechtenstein, Luxembourg, Macao SAR, Malta, Monaco, the Netherlands, New Zealand, Norway, Portugal, Qatar, San Marino, Singapore, Slovenia, Spain, Sweden, Switzerland, Taiwan (China), the United Arab Emirates, the United Kingdom, the United States.

UPPER-MIDDLE INCOME: Antigua and Barbuda, Argentina, Bahrain, Barbados, Brazil, Botswana, Chile, Croatia, the Czech Republic, Estonia, Gabon, Grenada, Hungary, Lebanon, Libya, Malaysia, Mauritius, Mexico, Oman, Palau, Panama, Poland, Repblica Bolivariana de Venezuela, the Republic of Korea and International Migration by Education Attainment, 19902000189 the Democratic Peoples Republic of Korea, St. Kitts and Nevis, St. Lucia, Saudi Arabia, the Seychelles, the Slovak Republic, Trinidad and Tobago, Turkey, Uruguay.

LOWER-MIDDLE INCOME: Albania, Algeria, Belarus, Belize, Bolivia, Bosnia and Herzegovina, Bulgaria, Cambodia, Cape Verde, Colombia, Costa Rica, Cuba, Djibouti, Dominica, the Dominican Republic, Ecuador, Egypt, El Salvador, Equatorial Guinea, Fiji, FYR Macedonia, Georgia, Guatemala, Guyana, Iraq, Islamic Republic of Iran, Jamaica, Jordan, Kazakhstan, Kiribati, Latvia, Lithuania, Maldives, the Marshall Islands, the Federated States of Micronesia,Morocco,Namibia, Papua New Guinea, Paraguay, Peru, the Philippines, Romania, Russia, St. Vincent and the Grenadines, Samoa, Serbia and Montenegro, South Africa, Sri Lanka, Suriname, Swaziland, the Syrian Arab Republic, Thailand, Tonga, Tunisia, Ukraine, Uzbekistan, Vanuatu.

LOW INCOME: Afghanistan, Angola, Armenia, Azerbaijan, Bangladesh, Benin, Bhutan, Burkina Faso,Myanmar, Burundi, Cameroon, the Central African Republic, Chad, China, the Comoros, the Democratic Republic of 
Congo, Cte dIvoire, Eritrea, Ethiopia, The Gambia, Ghana, Guinea, GuineaBissau, Haiti, Honduras, India, Indonesia, Kenya, Kyrgyzstan, Lao PDR, Lesotho, Liberia,Madagascar, Malawi, Mali, Mauritania, Moldova, Mongolia, Mozambique, Nepal, Nicaragua, Niger, Nigeria, Pakistan, the Republic of Congo, the Republic of Yemen, Rwanda, So Tom and Principe, Senegal, Sierra Leone, the Solomon Islands, Somalia, Sudan, Tajikistan, Tanzania, Togo, Turkmenistan, Uganda, Vietnam, Zambia, Zimbabwe.

By size. LARGE (above 25 million): China, India, the United States, Indonesia, Brazil, Russia, Pakistan, Bangladesh, Japan, Nigeria, Mexico, Germany, Vietnam, the Philippines, the Republic of Korea and the Democratic Peoples Republic of Korea, Turkey, Egypt, Islamic Republic of Iran, Ethiopia, Thailand, France, the United Kingdom, Italy, Ukraine, the Democratic Republic of Congo, Myanmar, South Africa, Colombia, Spain, Poland, Argentina, Tanzania, Sudan, Canada, Kenya, Algeria,Morocco, Peru.

UPPER MIDDLE (from 10 to 25 million): Uzbekistan, Republica Bolivariana de Venezuela, Nepal, Uganda, Iraq, Malaysia, Taiwan (China), Romania, Saudi Arabia, Afghanistan, Ghana, Australia, Sri Lanka, the Republic of Yemen,Mozambique, the Syrian Arab Republic, Madagascar, the Netherlands, Cte dIvoire, Kazakhstan, Chile, Cameroon, Cambodia, Zimbabwe, Ecuador, Angola, Mali, Burkina Faso, Guatemala, Malawi, Cuba, Greece, Niger, Serbia and Montenegro, Zambia, the Czech Republic, Belgium, Belarus, Portugal, Hungary.

LOWER MIDDLE (from 2.5 to 10 million): Tunisia, Senegal, Sweden, Somalia, the Dominican Republic, Bolivia, Azerbaijan, Guinea, Austria, Bulgaria, Haiti, Chad, Rwanda, Switzerland, Swaziland, Hong Kong (China), Honduras, Burundi, 190 Part II Brain Drain, Brain Gain, Brain Waste Benin, El Salvador, Tajikistan, Israel, Paraguay, the Slovak Republic, Papua New Guinea, Denmark, Lao PDR, Georgia, Libya, Finland, Nicaragua, Jordan, Kyrgyz Republic, Turkmenistan, Togo, Norway, Croatia, Sierra Leone, Moldova, Singapore, Bosnia and Herzegovina, Costa Rica, Ireland, New Zealand, the Central African Republic, Eritrea, Lithuania, Lebanon, the Republic of Congo, Uruguay, Palestine, Albania, Armenia, Panama, Liberia, the United Arab Emirates,Mauritania, Oman, Jamaica,

SMALL (lower than 2.5 million): Mongolia, Latvia, Kuwait, Bhutan, FYR Macedonia, Slovenia, Namibia, Lesotho, Botswana, Guinea-Bissau, Estonia, The Gambia, Trinidad and Tobago, Gabon, Mauritius, Fiji, Cyprus, Guyana, the Comoros, Timor-Leste, Bahrain, Djibouti, Qatar, Equatorial Guinea,Macao SAR, Cape Verde, the Solomon Islands, Luxembourg, Suri- 
name, Malta, Brunei Darussalam, The Bahamas, Maldives, Iceland, Barbados, Belize, Vanuatu, Samoa, So Tom and Principe, St. Lucia, St. Vincent, the Federated States of Micronesia, Tonga, Kiribati, Grenada, the Seychelles, Andorra, Dominica, Antigua and Barbuda, the Marshall Islands, St. Kitts and Nevis, Liechtenstein, Monaco, San Marino, Palau, Nauru, Tuvalu, Holy See (Vatican City).

\subsection{Countries in the sample}

Albania, Algeria, Antigua and Barbuda, Argentina, Australia, Austria, Bangladesh, Belgium, Benin, Bolivia, Botswana, Brazil, Bulgaria, Burkina Faso, Burundi, Cameroon, Canada, Chile, China, China Hong Kong SAR, Colombia, Comoros, Congo, Rep. of the, Costa Rica, Cote d'Ivoire, Denmark, Dominica, Dominican Republic, Ecuador, Egypt, El Salvador, Finland, Gabon, Gambia, The, Germany, Ghana, Greece, Grenada, Guatemala, GuineaBissau, Guyana, Haiti, Honduras, Hungary, India, Indonesia, Iran, Ireland, Italy, Jordan, Kenya, Korea, Lesotho, Madagascar, Malawi, Malaysia, Mali, Mauritania, Mauritius, Mexico, Morocco, Mozambique, Namibia, Netherlands, New Zealand, Nicaragua, Norway, Pakistan, Panama, Paraguay, Peru, Philippines, Portugal, Rwanda, Saint Kitts and Nevis, Saint Vincent and the Grenadines, Senegal, Singapore, South Africa, Spain, Sri Lanka, Swaziland, Sweden, Syria, Thailand, Togo, Trinidad and Tobago, Tunisia, Uruguay, Venezuela, Zambia, Zimbabwe

\section{$7 \quad$ References}

- Benhabib J. and Spiegel M. (1994), The role of human capital in economic development: Evidence from aggregate cross-country data. Journal of Monetary Economics, 34, 2 : 143174.

- Biao, Xiang, 2006, Promoting Knowledge Exchange Through Diaspora Networks (The Case of the People's Republic of China), in "Converting Migration Drains into Gains Harnessing the Resources of Overseas Professionals", edited by Wescott C. and J. Brinkerhoff, Asian Development Bank 
- Brinkerhoff J.M. (2006), Diaspora Mobilization Factors and Policy Options, in $\mathrm{n}$ " Converting Migration Drains into Gains Harnessing the Resources of Overseas Professionals", edited by Wescott C. and J. Brinkerhoff, Chap. 1, Asian Development Bank

- Chanda, Rupa, 2001, Trade in Health Services, Commission for Macroeconomics and Health Working Paper No. 4: 5.

- Cohen, D. and M. Soto (2001), Growth and human capital: good data, good results, CEPR Discussion Paper, n. 3025.

- Commander, S , Kangasniemi, M. and L. Alan Winters (2003), The Brain Drain: Curse or Boon?, IZA Discussion Paper No. 809

- De la Fuente, A., and R. Domenech (2006), Human capital in growth regressions: How much difference does data quality make?, Journal of the European Economic Association, 4(1), 136.

- Di Maria C. and P. Stryszowski (2006), Brain Drain and distance to Frontier, Discussion Paper 64, Tilburg University, Center for Economic Research

- Docquier, F. et A. Marfouk (2006), "International migration by educational attainment (1990- 2000)", in: Ozden, C. et M. Schiff (eds), International migration, remittances and the brain drain, Chap 5, PalgraveMacmillan.

- Kapur, D. (2001), Diasporas and Technology Transfer, Journal of Human Development, Vol. 2, No. 2

- Kuznetsov, Y. and C. Sabel (2006), "International Migratio of Talent, Diaspora Networks and Development: Overview of Main Issues", in Kuznetsov, Y. (eds), "Diaspora Networks and the International Migration of Skills", Chap. 1 The World Bank, Washington DC

- Islam, N. (2003), Productivity Dynamics in a large sample of countries: a panel study, Review of Income and Wealth, Series 49, Number 2: 247272

- Meyer, J. B. and M. Brown (1999), "Scientific Diasporas, a New Approach to the Brain Drain", Discussion Paper no. 41, Management of Social Transformation, UNESCO, Paris. 
- Nelson, R.R. and E.S. Phelps (1966), Investment in humans, technological diffusion and economic growth, American Economic Review 56: 69-75.

- Nickell, S. (1981), Biases in dynamic models with fixed effects, Econometrica, 49, 14171426

- Opiniano, J. and T. A. Castro, 2006, Promoting Knowledge Transfer Activities through Diaspora Networks: A Pilot Study of the Philippines, in "Converting Migration Drains into Gains Harnessing the Resources of Overseas Professionals", edited by Wescott C. and J. Brinkerhoff, Chap. 3, Asian Development Bank

- Pandey, A., Aggarwal,A., Devane,R. and Y. Kuznetsov (2006), The Indian Diaspora: A Unique Case?, in Kuznetsov, Y. (eds), "Diaspora Networks and the International Migration of Skills", Chap. 4, The World Bank, Washington DC

- Saxenian, A. (1999), Silicon Valley's New Immigrant Entrepreneurs, Public Policy Institute of California, San Francisco, CA.

- Saxenian, A. (2001) Bangalore, the Silicon Valley of India?, CREDPR.

- Saxenian, A.(2002), Local and Global Networks of Immigrant Professional in Silicon Valley. San Francisco: Public Policy Institute of California.

- Vandebussche, J.,Aghion, P., and C. Meghir (2006), Growth, distance to frontier and composition of human capital, Journal of Economic Growth, 11: 97-127

- Wescott C. and J. Brinkerhoff (2006) (edited by), Converting Migration Drains into Gains Harnessing the Resources of Overseas Professionals, Asian Development Bank

- Xie Chengjia, (2002), Some understanding of overseas Chinese associations, Study on the History of Overseas Chinese, September, issue 3 
Département des Sciences Économiques de l'Université catholique de Louvain

Institut de Recherches Économiques et Sociales

Place Montesquieu, 3

1348 Louvain-la-Neuve, Belgique 